\title{
Performance of high-resolution X-band radar for rainfall measurement in The Netherlands
}

\author{
C. Z. van de Beek ${ }^{1}$, H. Leijnse ${ }^{1}$, J. N. M. Stricker ${ }^{1}$, R. Uijlenhoet ${ }^{1}$, and H. W. J. Russchenberg ${ }^{2}$ \\ ${ }^{1}$ Hydrology and Quantitative Water Management Group, Department of Environmental Sciences, \\ Wageningen University, The Netherlands \\ ${ }^{2}$ Remote Sensing of Environment Group, IRCTR, Delft University of Technology, The Netherlands
}

Received: 20 July 2009 - Published in Hydrol. Earth Syst. Sci. Discuss.: 23 September 2009

Revised: 23 December 2009 - Accepted: 21 January 2010 - Published: 5 February 2010

\begin{abstract}
This study presents an analysis of 195 rainfall events gathered with the X-band weather radar SOLIDAR and a tipping bucket rain gauge network near Delft, The Netherlands, between May 1993 and April 1994. The aim of this paper is to present a thorough analysis of a climatological dataset using a high spatial $(120 \mathrm{~m})$ and temporal $(16 \mathrm{~s})$ resolution X-band radar. This makes it a study of the potential for high-resolution rainfall measurements with nonpolarimetric X-band radar over flat terrain. An appropriate radar reflectivity - rain rate relation is derived from measurements of raindrop size distributions and compared with radar - rain gauge data. The radar calibration is assessed using a long-term comparison of rain gauge measurements with corresponding radar reflectivities as well as by analyzing the evolution of the stability of ground clutter areas over time. Three different methods for ground clutter correction as well as the effectiveness of forward and backward attenuation correction algorithms have been studied. Five individual rainfall events are discussed in detail to illustrate the strengths and weaknesses of high-resolution X-band radar and the effectiveness of the presented correction methods. $\mathrm{X}$-band radar is found to be able to measure the space-time variation of rainfall at high resolution, far greater than what can be achieved by rain gauge networks or a typical operational C-band weather radar. On the other hand, SOLIDAR can suffer from receiver saturation, wet radome attenuation as well as signal loss along the path. During very strong convective situations the signal can even be lost completely. In combination with several rain gauges for quality control, high resolution X-band radar is considered to be suitable for
\end{abstract}

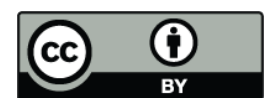

Correspondence to: C. Z. van de Beek (remco.vandebeek@wur.nl) rainfall monitoring over relatively small (urban) catchments. These results offer great prospects for the new high resolution polarimetric doppler X-band radar IDRA.

\section{Introduction}

Accurate measurement of precipitation in terms of its intensity and location is important for both hydrological research and operational water management. The more traditional method of measuring rainfall with rain gauges is less expensive than weather radar, but only provides point measurements and offers limited information on spatial rainfall variability (e.g., Ciach, 2003; Ciach and Krajewski, 2006). Other instruments such as disdrometers (Joss and Waldvogel, 1969) and microwave links (Leijnse et al., 2007a,b) provide more insight in the microstructure and the spatial average, respectively, of precipitation. However, these instruments cannot capture the spatial variability of rainfall over larger areas such as river catchments. Radar systems offer a way of measuring areal precipitation with both a high spatial and temporal resolution and therefore currently offer the best solution to measure this spatial variability.

The spatial resolution offered by radar systems can range from tens of meters for ground-based research radars up to several kilometers for space-borne systems, whereas the temporal resolution can range from seconds to days. C-band and S-band radars are more commonly used for operational precipitation measurements as these systems do not suffer as strongly from attenuation as radar systems with shorter wavelengths. Although X-band radars suffer more strongly from attenuation, they have the advantage of being able to measure at high spatial resolutions with only small antennas.

Published by Copernicus Publications on behalf of the European Geosciences Union. 
This makes X-band radar an affordable system for measuring rainfall at high spatial and temporal resolutions over distances where attenuation is not yet a major factor (e.g., Berne and Uijlenhoet, 2006; Uijlenhoet and Berne, 2008). As a result, this type of radar has recently received more attention in disciplines such as meteorology, (urban) hydrology and quantitative water management. While many radar systems only measure reflectivity, a growing number is capable of doppler and polarimetric measurements allowing far greater insight into precipitation (Bringi and Chandrasekar, 2001).

Before data gathered by radar systems can be routinely used for hydrologic applications it is necessary to correct for different types of error sources, which have been studied extensively in the past (e.g., Zawadzki, 1984; Austin, 1987; Joss and Lee, 1995; Sánchez-Diezma et al., 2001). The main error sources that need to be addressed are possible calibration errors, ground clutter and the effects of attenuation. While there are other possible error sources, e.g. Vertical Profile of Reflectivity and bright band, they are negligible for this weather radar as it measures close to the ground (less than $500 \mathrm{~m}$ ). The conversion from measured reflectivity values $(Z)$ to rain rates at ground level $(R)$ is another important step before radar data can actually be employed for research purposes or in operational hydrologic models. The most important ingredient of this conversion is a power-law $Z-R$ relation (e.g., Marshall and Palmer, 1948; Marshall et al., 1955), with coefficients that depend on the type of rainfall and the climatic setting (Battan, 1973; Uijlenhoet, 2001, 2008).

After identifying and correcting for a possible drift in radar calibration, non-precipitating echoes (so-called clutter) need to be identified and removed from the radar image. In this study a non-polarimetric radar (measuring reflectivities only) was employed, making the detection of ground clutter quite difficult. With modern-day polarimetric and/or doppler radar systems (e.g., Bringi and Chandrasekar, 2001; Meischner, 2004) identifying clutter has become easier, although a complete correction is still not trivial to achieve. Several methods have been proposed over the years to identify and correct for ground clutter. While none can fully remove the effects of clutter, it can be greatly reduced (e.g., Steiner and Smith, 2002; Berenguer et al., 2005; Unal, 2009).

At the wavelength at which X-band radars operate attenuation is another major factor causing erroneous rainfall estimates. This was already recognized in the early days of weather radar (e.g., Ryde, 1946; Atlas and Banks, 1951). Attenuation occurs both due to rainfall on the radar (wet radome attenuation) and along the beam path (Path Integrated Attenuation, PIA). The first method of correcting for attenuation was proposed by Hitschfeld and Bordan (1954) and is now generally known as the Hitschfeld-Bordan forward correction scheme. Due to the reduced cost of S- or C-band weather radars attention was moved from $\mathrm{X}$-band to these systems during the 1970s and 1980s. However, with the launch of the TRMM satellite (Simpson et al., 1988) in 1997 and the CASA project, where a complementary X-band radar network is being proposed (Chandrasekar and Lim, 2008), better attenuation correction schemes have become of major interest and new research into X-band radar has begun. Where Hitschfeld and Bordan (1954) proposed a simple forward scheme to correct for attenuation, more sophisticated backward methods, which use a Path Integrated Attenuation constraint, have been developed since (e.g., Marzoug and Amayenc, 1994; Delrieu et al., 1997).

With the recent installation of a new X-band radar, IDRA (Figueras i Ventura and Russchenberg, 2007, 2008), at the Cabauw Experimental Site for Atmospheric Research (CESAR) in The Netherlands (Russchenberg et al., 2005; Apituley et al., 2008), this study presents the analysis of a multiyear data set gathered with its predecessor, SOLIDAR. The aim is to find the strengths and weaknesses of X-band radar under conditions typical for The Netherlands using a large dataset consisting of 195 events and try to deal with the weaknesses in a straightforward way. Even though the proposed methodology is applied to an X-band radar over a surface with little height differences, it is generally applicable to any (non-polarimetric) radar system with minor modifications. This can also be considered an exploratory study for future research into the use of X-band radar for ground validation of the upcoming Global Precipitation Mission (GPM) (Stephens and Kummerov, 2007) in The Netherlands.

\section{Data and theory}

\subsection{Radar and gauge data}

This study employs data gathered by the X-band FMCW (Frequency Modulated - Continuous Wave) Solid-State Weather Surveillance Radar, SOLIDAR, which was located on top of the Electrical Engineering building of Delft University of Technology (Ligthart and Nieuwkerk, 1990). The data gathered for the purpose of this study were collected over a six year period, from January 1991 until August 1997 (Uijlenhoet et al., 1997). SOLIDAR received a major upgrade in the Winter of 1992-1993. The retrieval algorithm was improved and an additional $8 \mathrm{~dB}$ was added to radar reflectivity maps thus greatly improving the quality of the acquired data.

As shown in Table 1, the radar had a range resolution of $30 \mathrm{~m}$, which needed to be degraded to $120 \mathrm{~m}$ during preprocessing due to data storage constraints. It operated at a single elevation of $1.7^{\circ}$ and had a maximum range of $15.36 \mathrm{~km}$ at an angular resolution of $1.875^{\circ}$. The temporal resolution was just under $16 \mathrm{~s}$. Due to the location of a second radar on the roof of the same building SOLIDAR could not cover a full $360^{\circ}$ circle. This is the cause of the $120^{\circ}$ gap which can be seen southeast of the radar in Fig. 1.

The instrument was originally designed to measure rain rates of $1 \mathrm{~mm} \mathrm{~h}^{-1}$ up to $100 \mathrm{~mm} \mathrm{~h}^{-1}$. There is a considerable amount of low intensity clutter present in the data below the $1 \mathrm{~mm} \mathrm{~h}^{-1}(\sim 22.3 \mathrm{dBZ})$ threshold, but also several individual 


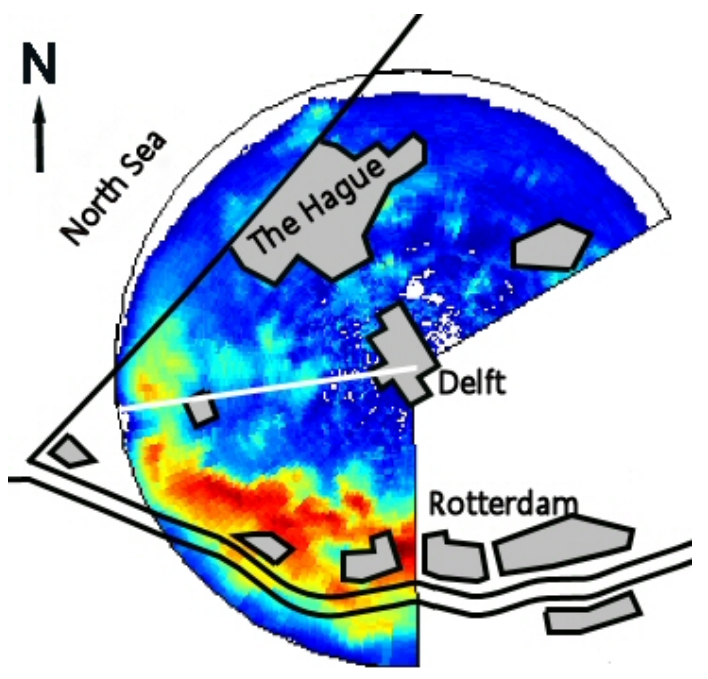

Fig. 1. Range and coverage of SOLIDAR. The white line indicates the line array of rain gauges, located from 3.75 to $10 \mathrm{~km}$ from the radar. Along this path the only significant clutter is present just beyond $6 \mathrm{~km}$, where the beam encounters buildings and greenhouses.

locations with reflectivities of up to $60 \mathrm{dBZ}\left(\sim 150 \mathrm{~mm} \mathrm{~h}^{-1}\right)$, of which the strongest is found nearly due north at $9 \mathrm{~km}$ distance. Little information about upgrades and calibration is available, which implies that possible calibration errors have to be found using the available reflectivity data, an assessment of which will be shown in the next section.

The rain gauges in the area covered by the radar were located nearly due west of SOLIDAR, in a line array of $3.75 \mathrm{~km}$ up to $10 \mathrm{~km}$ from the radar (see Fig. 1). The distances of the individual gauges were $3750 \mathrm{~m}, 5450 \mathrm{~m}, 6267 \mathrm{~m}, 7450 \mathrm{~m}$, $8006 \mathrm{~m}, 8006 \mathrm{~m}, 8050 \mathrm{~m}, 8864 \mathrm{~m}$, and $9550 \mathrm{~m}$ from the radar. The rain gauges were standard tipping-bucket gauges with a volume resolution of $0.2 \mathrm{~mm}$. These gauges were operated from March 1991 until April 1994. During this time period between one and nine gauges were operational simultaneously.

Motivated by the radar upgrade in the winter of 1992-1993 and the availability of rain gauge measurements until April 1994, the available radar and rain gauge data in the intermediate period have been selected for analysis here, resulting in a dataset of approximately one year of measurements. The storage of the radar data was limited to only reflectivity maps of precipitation events (based on 4 criteria) due to limited storage space. These criteria were based on both the measurements of SOLIDAR and those of 2 radiometers and 4 automatic rain gauges (not belonging to the line array). The criteria were (Ligthart and Nieuwkerk, 1990):

1. On a clear day the radiometers yield a noise temperature of around $40 \mathrm{~K}$ and during heavy rain $250 \mathrm{~K}$. A threshold of $82 \mathrm{~K}$ was set for the detection of rain.
Table 1. SOLIDAR specifications after processing (from Ligthart and Nieuwkerk, 1990).

\begin{tabular}{ll}
\hline Characteristic & Value \\
\hline Centre frequency & $9.467 \mathrm{GHz}$ \\
Beam width & $2.8^{\circ}$ \\
Angular resolution & $1.875^{\circ}$ \\
Covered sector & $240^{\circ}$ \\
Maximum range & $15.36 \mathrm{~km}$ \\
Range resolution & $120 \mathrm{~m}$ \\
Antenna revolution time & $\sim 16 \mathrm{~s}$ \\
Height of radar site & $92 \mathrm{~m}$ \\
\hline
\end{tabular}

2. One or more of the four rain gauges measure at least a rain rate of $2 \mathrm{~mm} \mathrm{~h}^{-1}$ over a 1 -min period.

3. Within the map at least one pixel exceeds a reflectivity value corresponding to $10 \mathrm{~mm} \mathrm{~h}^{-1}$.

4. At least 5500 of the 16384 pixels of the entire map exceed a reflectivity corresponding to a $2 \mathrm{~mm} \mathrm{~h}^{-1}$ threshold.

Of these stored data only events with more than $30 \mathrm{~min}$ of continuous radar images were selected for this study. These combined selection criteria yielded a total of 195 rainfall events. A visual inspection of these events based on both strength and shape of the measured reflectivity patterns led to a further subdivision of these data into 30 stratiform events, 23 strongly convective events, and a third category of 142 unidentified events.

Finally, a dataset of 446 raindrop size distributions gathered by Wessels (1972) in the period between 3 January, 1968 and 13 March, 1969 in The Bilt, The Netherlands has been used to derive relations between reflectivity, rain rate, and attenuation. The Drop Size Distribution (DSD) data was collected using a filter paper technique with an exposure surface of $20 \mathrm{~cm}^{2}$. The exposure time was dependent on the period over which Wessels judged the rain to be constant, i.e. rain drop size distribution and intensity. The resulting time intervals are between 1 and $50 \mathrm{~min}$.

\subsection{Rain rate estimation}

To relate the reflectivity $(Z)\left[\mathrm{mm}^{6} \mathrm{~m}^{-3}\right]$ measured by SOLIDAR to the rain rate at the ground $(R)\left[\mathrm{mm} \mathrm{h}^{-1}\right]$ radar theory has to be applied (Battan, 1973). The mean power $P_{r}[\mathrm{~W}]$ received from reflections by raindrops at a range $r[\mathrm{~km}]$ can be expressed as

$\overline{P_{r}}=C \frac{|\mathrm{K}|^{2}}{r^{2}} Z_{\mathrm{A}}(r)$,

where $C$ is the radar constant, which is a function of radar attributes such as the transmitted wavelength and antenna characteristics, and $|\mathrm{K}|^{2}$ is a coefficient related to the dielectric 
constant of water (which is approximately 0.93 ). The attenuated reflectivity $Z_{\mathrm{A}}\left[\mathrm{mm}^{6} \mathrm{~m}^{-3}\right]$ can be expressed as

$Z_{\mathrm{A}}(r)=Z(r) \exp \left[-\frac{2 \ln (10)}{10} \int_{0}^{r} k(s) \mathrm{d} s\right]$,

where $Z\left[\mathrm{~mm}^{6} \mathrm{~m}^{-3}\right]$ is the unattenuated reflectivity, and $k$ $\left[\mathrm{dB} \mathrm{km}^{-1}\right]$ the specific, one-way, attenuation. For rain rate retrieval from incoherent, single frequency, non-polametric radar measurements, the values of $Z, k$, and $R$ can be expressed as integrals over the raindrop size distribution $N(D)$ $\left[\mathrm{mm}^{-1} \mathrm{~m}^{-3}\right]$ according to

$Z=\frac{10^{6} \lambda^{4}}{\pi^{5}|K|^{2}} \int_{0}^{\infty} \sigma_{\mathrm{B}}(D) N(D) \mathrm{d} D$,

$k=\frac{1}{\ln 10} \int_{0}^{\infty} \sigma_{\mathrm{E}}(D) N(D) \mathrm{d} D$,

$R=6 \pi \times 10^{-4} \int_{0}^{\infty} D^{3} v(D) N(D) \mathrm{d} D$,

where $\lambda[\mathrm{cm}]$ is the wavelength at which the radar operates, $\sigma_{\mathrm{B}}\left[\mathrm{cm}^{2}\right]$ and $\sigma_{\mathrm{E}}\left[\mathrm{cm}^{2}\right]$ are the backscattering and extinction cross-sections, and $v\left[\mathrm{~m} \mathrm{~s}^{-1}\right]$ is the terminal fall velocity of raindrops.

Using the parameterization proposed by Beard (1976) for the raindrop terminal fall velocities and the Mie scattering theory for spherical particles (van de Hulst, 1957), values of $Z, k$ and $R$ can be computed from a raindrop size distribution dataset.

\section{Methodology and assessment}

Like any other (X-band) weather radar SOLIDAR may suffer from a possible calibration drift, ground clutter, and wetradome induced and path-integrated attenuation. Also a conversion from measured reflectivities aloft to rain rates at ground level has to be applied. To assess their impact in terms of rainfall measurement uncertainty and discuss possible correction procedures, each of these issues will be analyzed in more detail in this section. Section 4 will illustrate these issues by means of several case studies.

\subsection{Radar calibration}

Many techniques for radar calibration exist (Stratmann et al., 1971; Joss and Lee, 1995; Atlas, 2002) and have also been described for space-borne and polarimetric radars (Gage et al., 2000; Gorgucci et al., 1992). As original calibration reports are not available for this radar, a possible drift in calibration can be inferred from a long-term comparison of the accumulated rainfall from the radar and the nearest gauge for a large number of events. Figure 2 shows the results for cases with more than $1 \mathrm{~mm}$ event total for the dataset described in Sect. 2, resulting in 95 events. Here the radar rain rate estimates have been calculated using the theoretical $Z-R$ relation that will be derived in Sect. 3.3. As can be seen in Fig. $2 b$ there is no clear trend in the radar event sums compared to that measured by the gauge, although there are more cases with underestimation than overestimation by the radar. Overestimation by the radar mainly occurs for low rainfall intensities. For intensities exceeding $2 \mathrm{~mm} \mathrm{~h}^{-1}$ the radar underestimates rainfall in nearly all cases.

Another way of finding a possible trend in radar calibration is to look at the average reflectivity of an area affected by strong ground clutter (Fig. 3). For this purpose the strongest clutter area in the radar image (nearly due north of the radar at $9 \mathrm{~km}$ ) was selected. The analysis was limited to all radar images during the period between May 1993 and October 1996 for which more than 2 min of continuous reflectivity data were available. The selected area consists of the 9 pixels in the center this ground clutter area. The data in Fig. 3 also seem to suggest a seasonal trend in reflectivity with the highest values around September and lowest around March. As only 3 years of data is available such a seasonal effect is highly uncertain and is therefore ignored for the remainder of this article. As can be seen in Fig. 3, the linear regression line through the dots suggests a gradual change in the level of reflectivity over time,

$\mathrm{dB} Z=42.86-0.0083 \times t$,

where the first term is the offset for the first measurement day on 15 May, 1993, and the second term the decrease in reflectivity level per day beyond this date. Based on this fit, that is based on three and half years of data, the reflectivity data of the 195 events between May 1993 and May 1994 were corrected. Figure 2c illustrates the result of this correction applied to the analysis shown previously in Fig. 2b. The data now seems to be overcorrected with a slight upward trend even though there is now as much radar overestimation as underestimation. The fact that this correction seems too strong for application during the period of the 195 selected events suggests that the calibration monitoring only occurred until early 1994 and that afterwards calibration drift set in. Hence, while a calibration drift was found, based on the overcompensation shown in Fig. 2c it was decided not to apply any correction to the reflectivity data for the 195 selected events.

\subsection{Ground clutter correction}

The next step in creating hydrologically useful rainfall maps is to correct the original data for clutter. Ground clutter occurs when the radar beam is reflected by objects on the ground such as buildings, trees, or mountains. Other types of clutter, such as sea clutter and reflections caused by swarms of insects, birds or airplanes, are also possible. One approach 

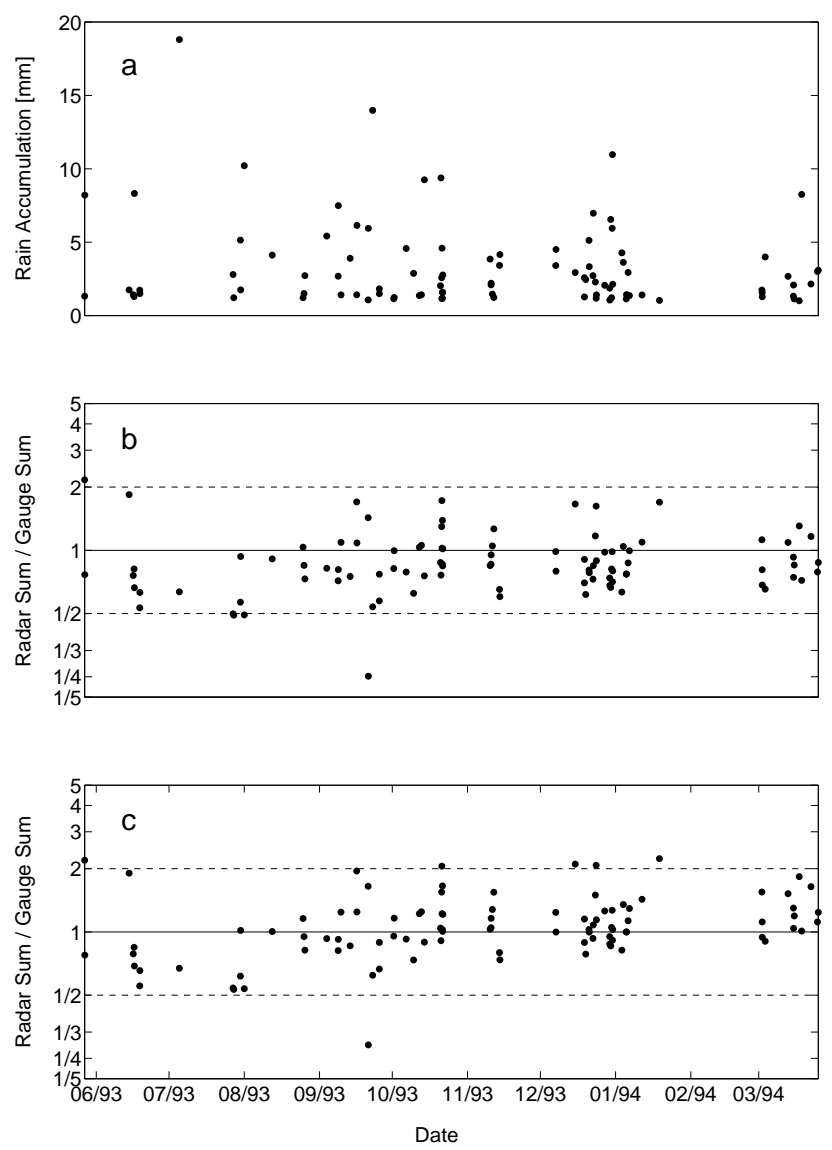

Fig. 2. (a) Rainfall accumulations larger than $1 \mathrm{~mm}$ of the gauge nearest to the radar (95 events in total). (b) Ratios of the rainfall accumulations of the radar and the nearest gauge for the same events as in a (the dashed lines indicate a factor 2 over- or underestimation). (c) Same as b after correction for possible calibration drift.

to identify clutter in the reflectivity data is to create a static map of areas where clutter is most prevalent. Another is to create a more dynamic map which identifies clutter from image to image. The problems of ground clutter in reflectivity maps and the associated identification and correction schemes have been extensively described (Aoyagi, 1983; Andrieu et al., 1997; Creutin et al., 1997; Steiner and Smith, 2002; Siggia and Passarelli, 2004; Berenguer et al., 2005). The more advanced techniques using doppler or polarimetric radar data cannot be applied on the data gathered by SOLIDAR as only the reflectivity data is available. In this study the ground clutter is therefore identified by creating a static clutter map on a polar grid based on the exceedance of a threshold value for more than $90 \%$ of the time for dry events. The selected threshold is $22.3 \mathrm{dBZ}$, which corresponds to the $1 \mathrm{~mm} \mathrm{~h}^{-1}$ originally given as the minimum detectable signal level for SOLIDAR (Ligthart and Nieuwkerk, 1990). Based on this clutter map three correction methods are tested: nearest neighbour, inverse distance, and tracking. The methods

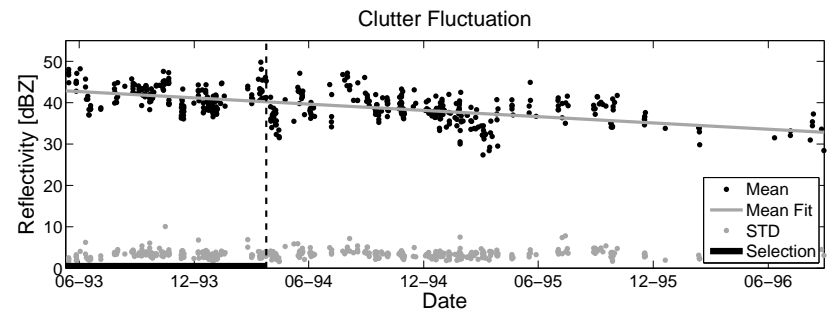

Fig. 3. The average radar reflectivity and standard deviation of the center 9 pixels of the strongest clutter area (nearly due north of the radar) for all events containing more than 2 min of continuous data between 5 May 1993 and 2 October 1996. Black dots represent the average values per event before correcting for calibration drift. Gray dots are the standard deviations (STD) for the clutter area. The black line is the linear fit through the average values. The period indicated by "Selection" corresponds to the events selected for the radar - rain gauge comparison (Fig. 2).

are applied on a polar grid as the local deformation of the polar grid with respect to the Cartesian grid is minor even though the sizes of the pixels vary with distance on a polar grid. Due to the large amount of data the authors chose to apply the corrections on the polar grid to reduce computer processing time.

The nearest neighbour method compares the identified clutter map to the current radar image with the reflectivity in $Z\left[\mathrm{~mm}^{6} \mathrm{~m}^{-3}\right]$. At each location marked as clutter the surrounding pixels that have not been marked as clutter are averaged and taken as value for the clutter location. If the window is not large enough to contain non-clutter pixels the range is extended until $70 \%$ of the outer edge of the window contains non-clutter pixels. While the $70 \%$ is a fairly arbitrary value it was found to perform well for after testing several cases.

The second method of clutter correction applies the inverse distance method to the clutter area using all points not marked as clutter as reference, using the following equation:

$Z_{i}=\frac{\sum_{k=1}^{N} d_{k}^{-p} Z_{k}}{\sum_{k=1}^{N} d_{k}^{-p}}$,

where $Z_{i}$ is reflectivity of the clutter pixel that needs to be corrected, $k$ is the index of the pixel at a distance $d_{k}$ from the clutter pixel, and $p$ determines the strength of the weights. In this manner each known (precipitation) pixel value is given a weight based on the inverse of the distance to the location of the unknown (clutter) pixel value. The power $p$ can be given any (positive) value, with larger values giving more weight to values closer to the location of interest. For this study a value of 2 was chosen to give some weight to values closer to the pixel of interest and still not be so large as to approach the nearest neighbor method. The maximum range was set to include only pixels in a range of up to $2 \mathrm{~km}$. This range was 
chosen to be large enough to ensure that non-clutter reference pixels were included even for larger clutter areas.

For the final method of clutter correction the movement of precipitation is tracked for each pixel. The tracking is done by taking a $5 \times 5$ pixel box with the pixel of interest as the center pixel. This window is then moved along a larger $19 \times 19$ pixel window in the previous image and the sum of the squared differences for each location is calculated. This results in a $15 \times 15$ pixel field with estimated sums of the squared differences. With the selected window size precipitation with a velocity of up to $\sim 190 \mathrm{~km} \mathrm{~h}^{-1}$ will be included. Therefore it is highly unlikely that any pixel, correctly identified as precipitation, will not be present in the selected window. The shift between the pixel of interest and the pixel with the lowest value of the sum of squared differences for the estimated $15 \times 15$ field is then assumed to be the movement for this pixel. As this system is not completely robust, the most common movement in a $5 \times 5$ pixel window around the clutter pixel is taken as the true movement for this window. Using this movement the precipitation value from the previous image is used to replace the clutter-affected pixel in the current image.

By marking random pixels as if they represent clutter the effectiveness of the three clutter correction methods can be tested. The test sizes are $1 \times 1,3 \times 3$ and $5 \times 5$ pixels. Figures 4 and 5 show 9 scatter plots of the corrected reflectivities for the 3 presented correction methods and 3 different clutter area sizes (applied to all cases, representing a total of 51559 images). From these plots it is clear that the nearest neighbor method gives the best results. The inverse distance method performs worse with larger scatter and lower fitted slope. Finally the tracking method also has a larger amount of scatter along the fitted line than the nearest neighbor method, but does have a fit that remains closer to the 1:1 line even for larger clutter areas.

Similar conclusions can be drawn on the basis of the statistics corresponding to these plots, as shown in Table 2. Here the bias represents the mean difference and the RMSE the root mean square difference between the estimated and the measured values. Table 2 shows that the bias is lowest for the nearest neighbour method for a clutter area size of one pixel. For larger areas the tracking method actually results in a smaller bias. As mentioned before, this can be seen from the linear fit through the data in Fig. 4. The fit remains closer to the 1:1 line for the tracking method for increasing clutter area sizes, even though the scatter is larger for the tracking and the inverse distance methods as compared to the nearest neighbour method. This is also clear from the RMSEvalues shown in Table 2. The nearest neighbour method has the smallest RMSE for all clutter area sizes, but it increases more rapidly than that of the other two methods. From these results it can be concluded that in general the nearest neighbour method performs better for small clutter areas, whereas the tracking method might perform better for clutter areas larger than the tested $5 \times 5$ pixel area.
Table 2. Bias [mm] and RMSE [mm] of the presented clutter correction methods for different clutter area sizes.

\begin{tabular}{lccc}
\hline \multirow{2}{*}{ clutter area } & nearest neighbour & inverse distance & tracking \\
\hline 1 pixel & 0.156 & 0.685 & 0.373 \\
9 pixels & 0.640 & 0.915 & 0.431 \\
25 pixels & 0.797 & 0.924 & 0.498 \\
\hline \multicolumn{4}{c}{ RMSE } \\
clutter area & nearest neighbour & inverse distance & tracking \\
\hline 1 pixel & 0.892 & 1.821 & 1.782 \\
9 pixels & 1.418 & 2.323 & 1.864 \\
25 pixels & 1.720 & 2.526 & 1.977 \\
\hline
\end{tabular}

Figure 5 shows the same results as Fig. 4, but the reflectivities have now been converted to rain rates. As expected, the results are similar, although the difference between the linear fits for the nearest neighbor and tracking methods are more pronounced. This is mainly because the logarithmic $\mathrm{dBZ}$ scale has been converted to a linear $R$-scale, giving increased weight to higher values. Because most clutter areas present in the SOLIDAR images are smaller than 25 pixels, as well as for reasons of computational ease, the nearest neighbor method has been applied in the remainder of this paper. An example is shown in Fig. 6, where Fig. 6a is the image before applying the nearest neighbor correction and Fig. $6 \mathrm{~b}$ the image after correction. While some clutter is still visible, the nearest neighbor method has been able to remove most of the clutter. Figure $6 \mathrm{c}$ and $\mathrm{d}$ will be discussed in Sect. 3.4.

\subsection{Derivation of $Z-R$ relations}

The conversion from a reflectivity of a volume in the air, $Z$, measured by a radar to a rain rate estimate at the ground, $R$, is difficult. As mentioned in the introduction many studies have been performed to find an answer to this problem (Marshall and Palmer, 1948; Marshall et al., 1955; Battan, 1973; Uijlenhoet, 2001). This study uses the dataset of drop size distributions from Wessels (1972), which allows powerlaw relations between $Z$ and $k$ as well as between $Z$ and $R$ to be established (see Fig. 7) using the theory discussed in Sect. 2.2. To estimate the coefficients of these relations $\ln (Z)-\ln (R)$ and $\ln (Z)-\ln (k)$ linear fits as well as a powerlaw non-linear fits have been established, both using leastsquares regression methods. The fits found for both methods are quite different and illustrate the importance of choosing the appropriate fit. In addition, they show that there is a significant amount of uncertainty associated with any fitting procedure. For the purpose of this study, the non-linear power-law fits have been chosen, as they give larger values greater weights. The values found for this theoretical fit were $Z=171 R^{1.73}$ and $k=1.04 \times 10^{-4} Z^{0.80}$. 

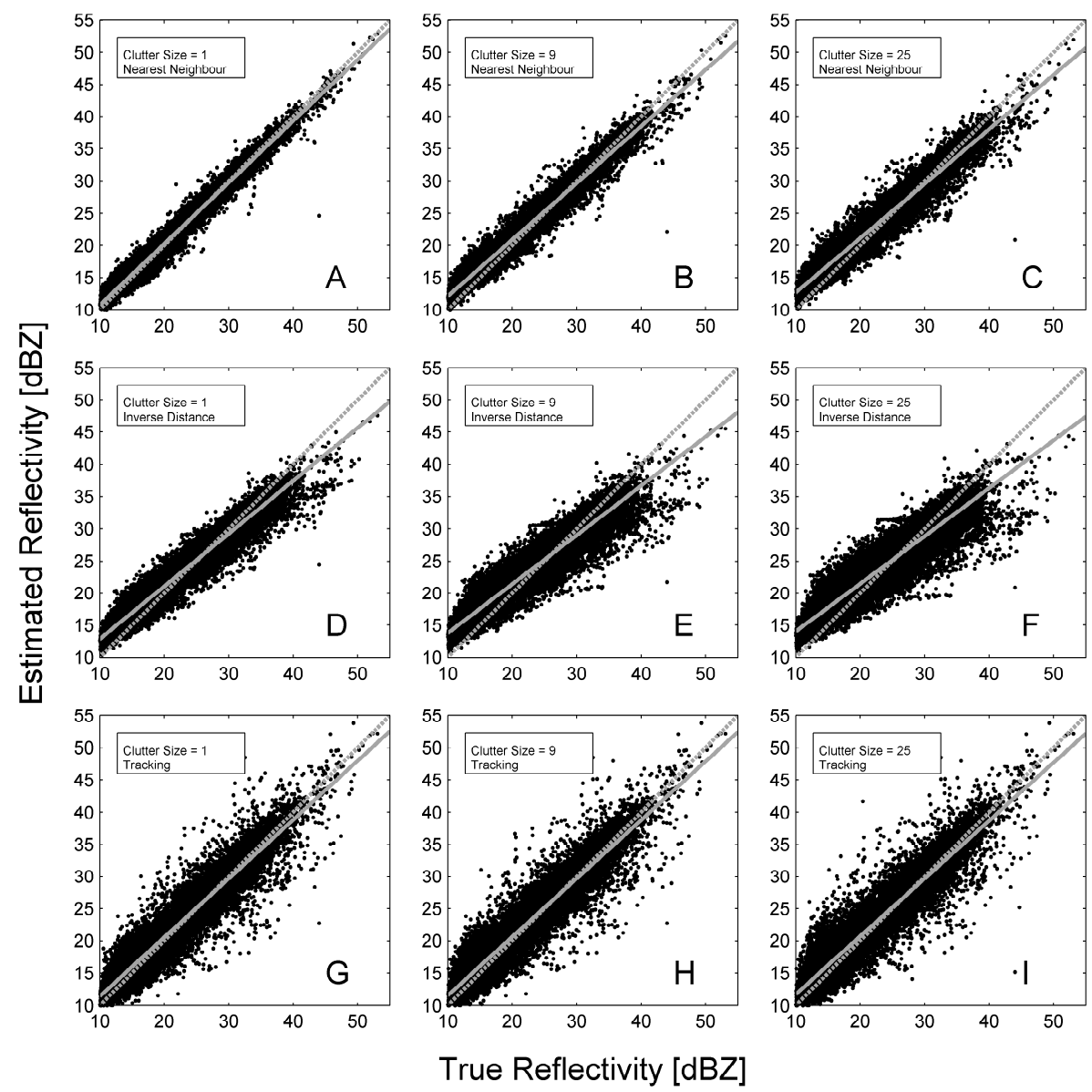

True Reflectivity [dBZ]

Fig. 4. Scatter plots of measured reflectivity versus estimated reflectivity. The rows represent the nearest neighbor, inverse distance and tracking methods and the columns $1 \times 1,3 \times 3$, and $5 \times 5$ pixel clutter areas. The solid lines represent linear fits through the data and the dashed lines are the 1:1 lines.

Another way to derive $Z-R$ relations is to directly compare measured radar reflectivities with rain gauge measurements at the ground. In order to do so we have chosen to estimate the average rain rates for both rain gauge and radar per time interval between subsequent tips of the bucket of a gauge. For this purpose the tips of the gauge nearest to the radar (at a distance of $3.75 \mathrm{~km}$ ) have been compared with the radar pixel directly over the gauge, which yields instantaneous values of $Z$ every $16 \mathrm{~s}$. This gauge was selected as the effect of attenuation will be smallest. In Fig. 8 all data is plotted, where the reflectivity values are plotted in $\mathrm{dBZ}$ and $R$ is plotted on a logarithmic scale to provide more detail for smaller reflectivity values. The $Z-R$ relation for all data was found to be $Z=59 R^{1.94}$ (see Fig. 8a). In Fig. $8 \mathrm{~b}$ and c $Z-R$ relations are also plotted for fits based only on convective and stratiform events, which have been selected from visual inspection of all events. This resulted in a $Z-R$ relation of $Z=120 R^{1.57}$ for stratiform events and $Z=40 R^{2.07}$ for convective events. The strongest outliers for the convective cases can be seen for low reflectivity values and high rain rates. This is in line what could be expected for strongly convective events, where signal saturation might occur as well as an attenuated signal due to a wet radome. Most of the low reflectivity outliers at rain rates above $20 \mathrm{~mm} \mathrm{~h}^{-1}$ in Fig. 8 can be traced back to a few events during the summer months of 1993, when several high intensity convective events occurred.

The theoretical fit (see Fig. 7) is quite different from the fits found based on the radar-gauge comparison and gives lower rain rates than found from the radar-gauge fit, as can be seen from the fitted lines in Fig. 8d. In this figure the dash-dotted line is the theoretical fit, the solid line the fit for all cases, the dotted line for convective cases and the dashed line for stratiform cases. The convective fit and the fit for all cases are very similar, as could be expected when looking at the data. Most of the largest scatter occurs with convective events and therefore the most extreme values for all data points are those related to these convective evens. The slope of the fitted stratiform relation is steeper than the slopes of the convective and all-event relations. At lower rainfall intensities it does lie closer to the theoretical fit, but beyond $6.5 \mathrm{~mm} \mathrm{~h}^{-1}$ the other fits lie closer to the theoretical fit. 


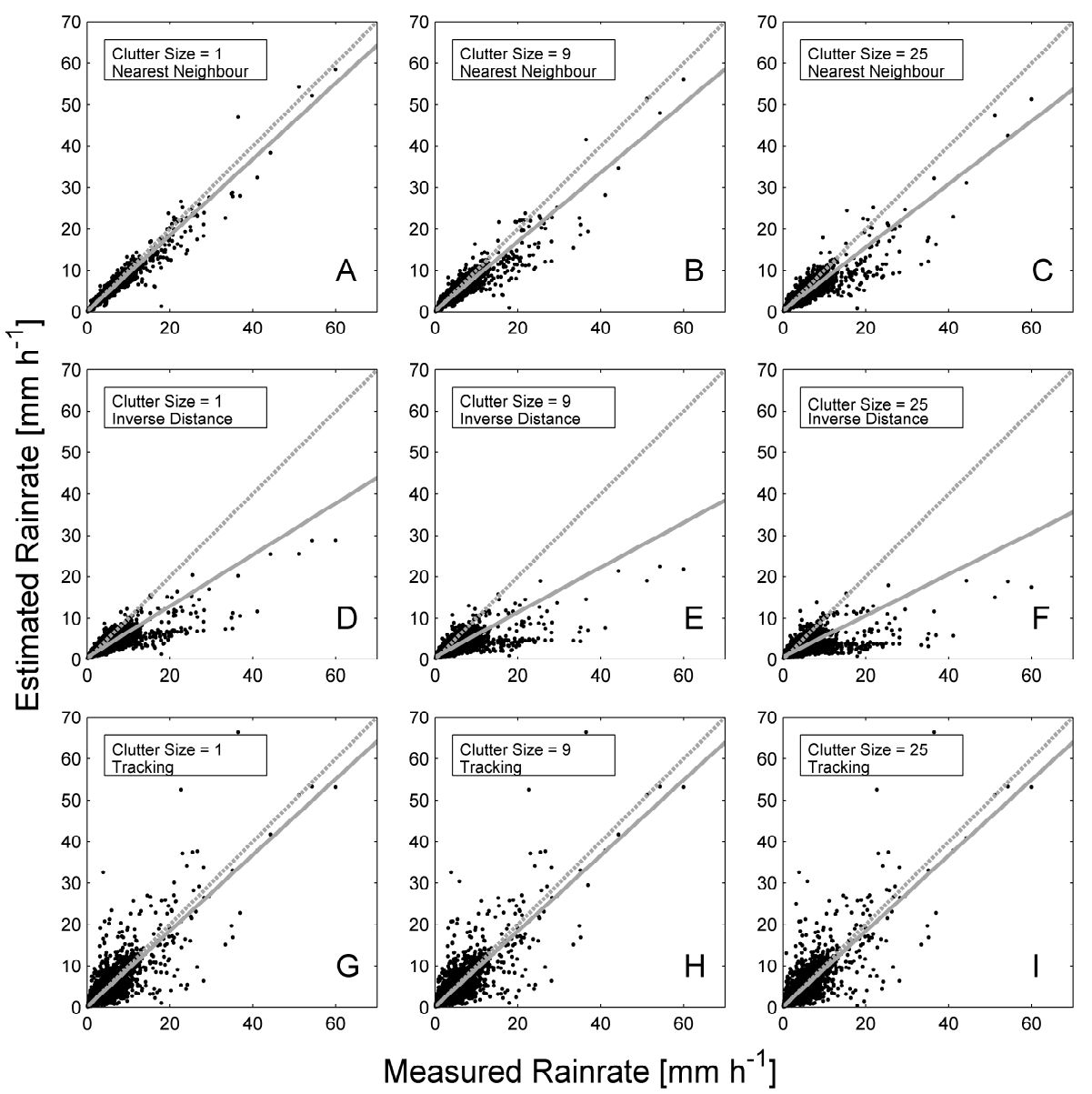

Fig. 5. Same as Fig. 4, but in terms of rain rate.

The discrepancy between the raindrop size distribution based fit and the radar-gauge based fits can be attributed to several causes, such as: 1) errors in the collected drop size distribution dataset; 2) limitations in expressing the $Z-R$ relation as a simple power-law function; 3 ) lack of consistency between point measurements of rainfall at the ground and reflectivities in volumes of the air; 4) radar calibration errors; 5) strong attenuation in convective events causing lower than average $Z$-values for gauge-measured rain rates. While none of the power-law relations will be universally applicable for every precipitation type, we have chosen to use the theoretical $Z-R$ relation as the errors involved are expected to be smaller than those for the fit found using the radar-gauge comparison. Also, maybe even more importantly, the theoretical fit is independent of the gauge data which we use for the validation of the radar data.

\subsection{Attenuation correction}

The most common way to correct for attenuation suffered by non-polarimetric radars is by estimating the corrected (unattenuated) rainfall rate $R_{\mathrm{C}}$ from the measured (attenu- ated) reflectivity $Z_{\mathrm{A}}$ using the equation originally proposed by Hitschfeld and Bordan (1954), assuming $Z=a R^{b}=c k^{d}$ :

$R_{\mathrm{C}}(r)=\frac{\left(Z_{\mathrm{A}}(r) / a\right)^{1 / b}}{\left[1-\frac{2 \ln (10)}{10 d} \int_{0}^{r}\left(\frac{Z_{\mathrm{A}}(s)}{c}\right)^{1 / d} \mathrm{~d} s\right]^{d / b}}$.

Using this equation the radar image can be corrected for attenuation. A major problem with the Hitschfeld-Bordan equation is the fact that it is numerically unstable, as the denominator in Eq. (8) may get close to zero or even become negative. Setting a constraint on the total correction is therefore necessary. As the radar calibration was uncertain this value was set to $10 \mathrm{~dB}$, as suggested by Delrieu et al. (1999). The integral in the denominator goes from 0 to $r$ and, as a result, the equation effectively corrects for the attenuation outwards from the radar. Therefore it is called a forward algorithm. An example is shown in Fig. 6b and d. In this figure the amount of correction along the path of the radar beam can be seen. Beyond the strong clutter areas shown in Fig. 6a the correction is fairly strong and after clutter removal this effect is greatly reduced. 


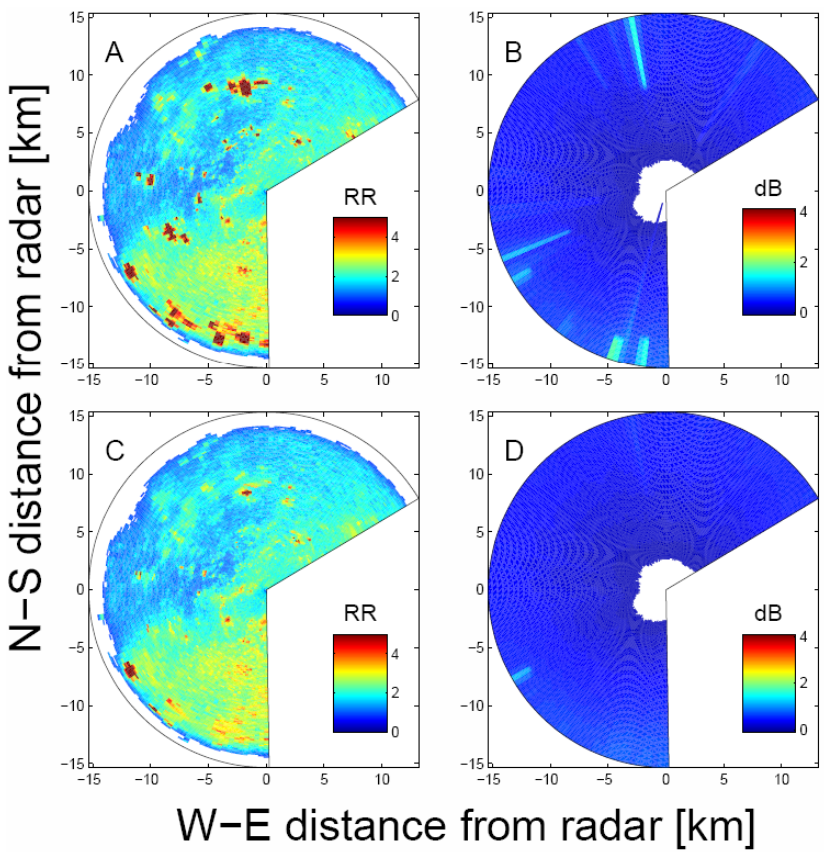

Fig. 6. Illustration of clutter correction. (A) shows the image before correction and (B) the corresponding amount of attenuation correction applied using the Hitschfeld-Bordan forward method (Sect. 3.4). The lower two panels are similar to the upper panels, but with a nearest neighbor clutter correction applied to the image. The clutter area in the southwest that was not removed in this figure is a clutter region that appeared for the first time on 1 October 1993, and remained visible for the remainder of the measurements.

Another method to correct for attenuation is to use a reference point at a distance $r_{0}$ from the radar to calculate the Path Integrated Attenuation (PIA) and from that point use a backward algorithm (Marzoug and Amayenc, 1994). This algorithm has been designed to avoid the instability problem found with the forward algorithm. The equation to derive the corrected rain rate $R_{\mathrm{C}}$ from the measured reflectivity $Z_{\mathrm{A}}$ has a similar functional form as the forward algorithm:

$$
R_{\mathrm{C}}(r)=\frac{\left(Z_{\mathrm{A}}(r) / a\right)^{1 / b}}{\left[A_{0}^{1 / d}+\frac{2 \ln (10)}{10 d} \int_{r}^{r_{0}}\left(\frac{Z_{\mathrm{A}}(s)}{c}\right)^{1 / d} \mathrm{~d} s\right]^{d / b}} .
$$

Although the equation basically looks the same as the forward equation, it requires the PIA and the integral goes from the reference range $r_{0}$ towards the radar instead of outward from the radar. Here $A_{0}=A\left(r_{0}\right)$ is the exponential factor in Eq. (2) evaluated at the range $r=r_{0}$, accounting for the (twoway) PIA between the radar antenna and the reference target. To find this value for a reference point a known clutter area, such as buildings or mountains, can be used but rain gauges as well. In The Netherlands the benefit of a backward algorithm is limited in general, as it is hard to find enough reference points in this mostly flat country. Fortunately, at-
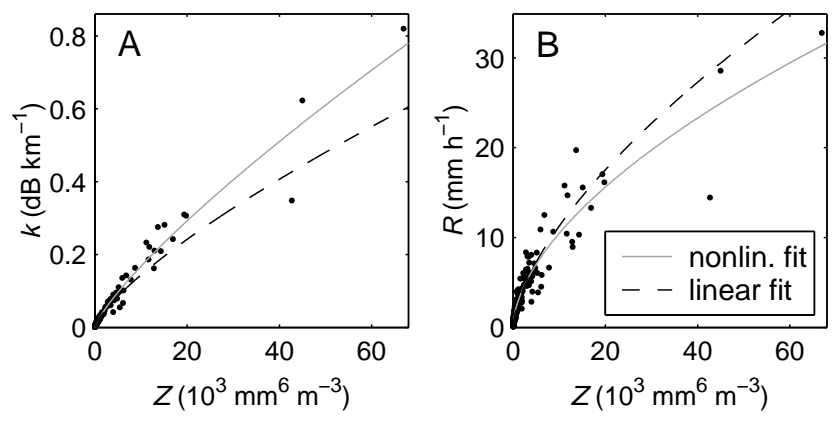

Fig. 7. (Left) $Z-k$ relation derived from raindrop size distribution data using both a linear and a non-linear power-law fit. (Right) Idem for $Z-R$ relation (from Leijnse et al., 2008).

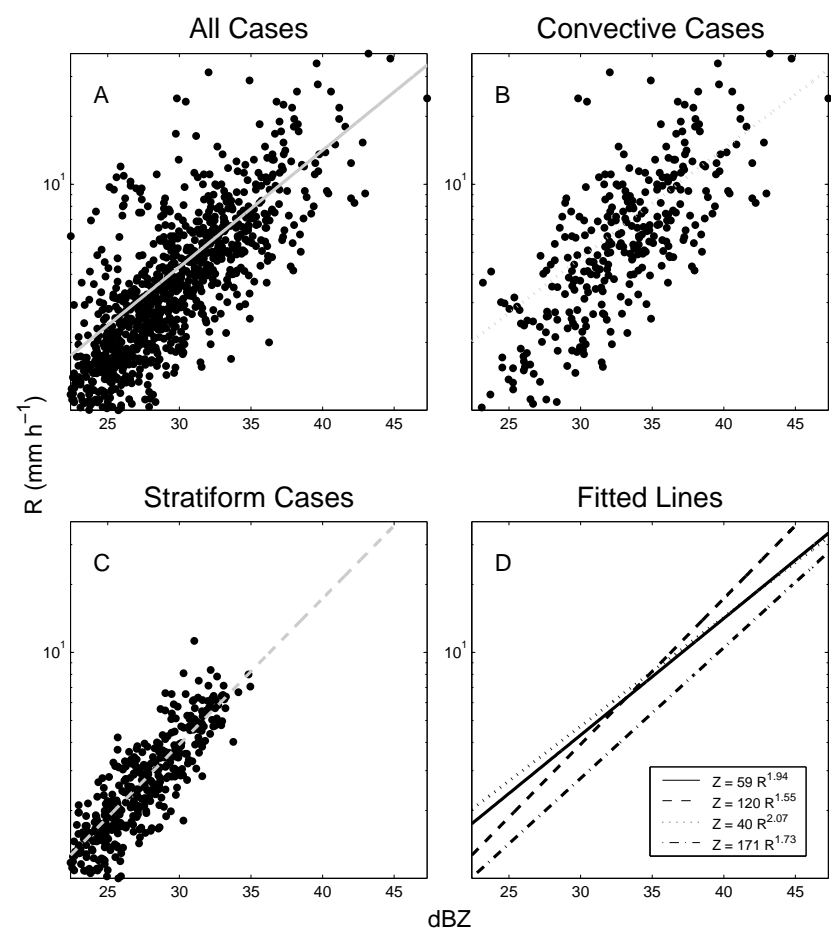

Fig. 8. $Z-R$ relations derived from nearest gauge data and measured radar reflectivities by applying a non-linear power-law fit. All cases are fitted in (A). Convective cases and stratiform cases are plotted in (B) and (C). All fits are plotted together in (D), where the solid line indicates the estimated relation through all data, the dotted line the fit through the convective data, the dashed line the fit through the stratiform data and the dash-dotted line the fit through the theoretical data.

tenuation is generally not a major problem in a climate such as that of The Netherlands, where extreme rain rates over extended areas do not frequently occur. Even if there are not enough reference points to correct the entire image with a backward algorithm, it can be used for verification of the forward algorithm at a limited number of locations. 
While both correction algorithms have been found to work fairly well, they have some limitations, mainly associated with the underlying assumptions:

1. The radar is calibrated perfectly.

2. The values of the coefficients and exponents of the $Z-R$ and $Z-k$ relations hold for the entire path over which the correction takes place.

3. The value for $A_{0}$ at the reference range employed in the backward algorithm is known accurately.

Due to a lack of reference points for correcting the entire radar image using the backward method, the forward method is used to correct all events in this paper. To illustrate the accuracy of the backward method compared to the forward method both will be compared in more detail for a few selected events in Sect. 4. While it is not possible to correct the entire radar image it is possible to use the gauge furthest along the line array as a reference point to estimate the PIA.

The amount of attenuation correction increases with distance from the radar. Figure 9 shows the average rain rate for all events as a function of the distance from the radar in the direction of the line array of gauges. As can be seen in Fig. 9a the attenuation correction only has a small influence on the average rain rate even after $6 \mathrm{~km}$, where a clutter area is present due to the edge of a greenhouse area. In Fig. $9 \mathrm{~b}$ the clutter has been removed, which results in a slightly reduced average attenuation correction. In Fig. 9c this difference can be seen, where the dashed line indicates the difference of the non-clutter-corrected values and the solid line that of the clutter-corrected ones. At the furthest range this effect becomes around $10 \%$ of the inferred rain rate. While these figures do not suggest a huge impact of attenuation correction on average, it actually does have a significant impact on individual strongly convective cases. This will be shown in the case study in Sect. 4, where the correction reaches values of more than $80 \mathrm{~mm} \mathrm{~h}^{-1}$.

The improvement of attenuation correction over uncorrected values is also illustrated in Fig. 10a, which shows the results of our analysis in a scatter plot. Not only does the scatter reduce slightly, but the slope of the linear fit increases from 0.57 to 0.65 . As the slight positive offsets of the fitted functions suggest, the radar tends to overestimate for cases with event totals of less than $3 \mathrm{~mm}$. For higher event totals the radar will mostly underestimate. When looking only at the strongly convective as well as the stratiform cases in Fig. 10b, results improve in both cases. The fit is closest to the 1:1-line for the convective cases with a slope of 0.77 , but has a large amount of scatter. For the stratiform cases the scatter is very small, even though there is still an underestimation for higher rain rates, very similar to that of the fit through all cases. As mentioned before, this underestimation at higher rain rates can be explained partly by wet-radome attenuation and in some cases receiver saturation. As was
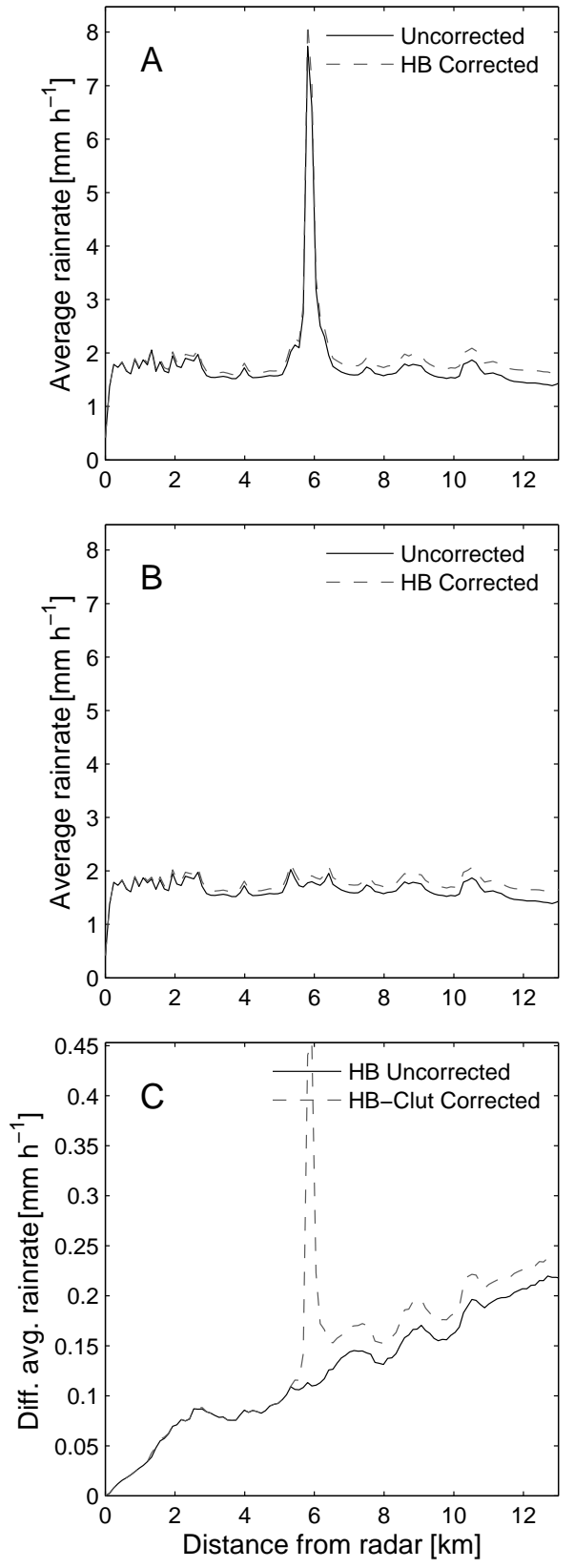

Fig. 9. Effect of both clutter correction and attenuation correction along the radial in the direction of the line array of rain gauges, averaged over all cases. (A) Shows the original data uncorrected for both clutter and attenuation (solid line) and only corrected for attenuation (dashed line). (B) Is the same after correction for clutter, which effectively removes the peak at $6 \mathrm{~km}$ from the radar. (C) Illustrates the difference between the attenuation correction of figures (A) and (B) and the effect of clutter on the attenuation correction past $6 \mathrm{~km}$.

shown in Sect. 3.3, the employed $Z$ - $R$ relation based on DSD data gives lower estimates than found using the gauge-radar fit. Therefore an underestimation as seen in these figures is 

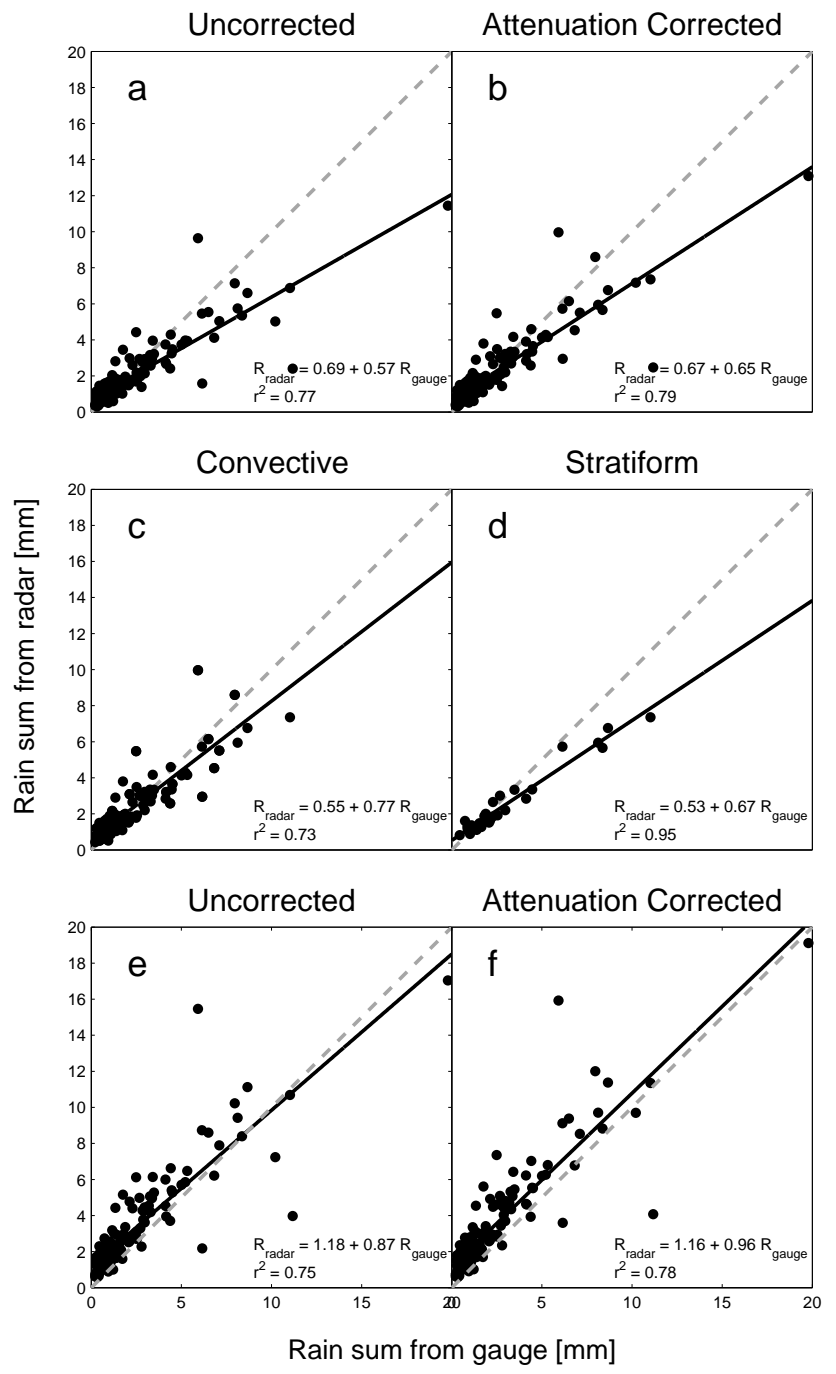

Fig. 10. Scatter plots of rainfall accumulation from radar and rain gauge for each case. The uncorrected cases using the theoretical $Z-R$ relation are shown in (a) and the attenuation-corrected cases in (b). Only strongly convective cases are shown in (c) and only large-scale stratiform cases in (d). (e) and (f) are the same as (a) and (b), but now using the $Z-R$ relation found from the gauge-radar comparison for all data.

not unexpected and suggests that a fit closer to the one found with the radar-gauge data should give better results for this radar. Figure 10c is the same plot as Fig. 10a, but now using the $Z-R$ relation found from the comparison of the gauges with the reflectivities for all cases. As could be expected, this fit indeed provides a far better agreement between radar and gauge, with a slope of 0.87 for uncorrected and 0.96 for attenuation corrected events. As mentioned in Sect. 3.3, the theoretical fit is used for this study, even though the other gives better results, because the theoretical fit is independent of the gauge data.

\section{Case studies}

In this section five events are studied in greater detail to illustrate both the strengths and challenges of X-band radar, as well as the performance of the correction methods.

\subsection{Event 1: light precipitation}

This event illustrates precipitation observation below the radar threshold of $1 \mathrm{~mm} \mathrm{~h}^{-1}$. On 15 May 1993, low intensity precipitation passed over or near the gauges in the early morning between 06:00 a.m. and 08:00 a.m. (see Fig. 11). From 06:15 a.m. the rain can be seen to move slowly from the southwest and to reach the radar around 06:30 a.m. after which a drop in reflectivity for both the major clutter location north of the radar, as well as the total measured reflectivity level of the map is apparent, as shown in Fig. $11 \mathrm{k}$ and 1 . This precipitation has a very low intensity of around $0.2 \mathrm{~mm} \mathrm{~h}^{-1}$, until a small peak of $1 \mathrm{~mm} \mathrm{~h}^{-1}$ is seen at 07:30 a.m. at the gauge at $3.75 \mathrm{~km}$ from the radar.

As can be seen in Fig. 11a-d this event causes problems for SOLIDAR as this is very near to the minimum detectable reflectivity of $9.05 \mathrm{dBZ}\left(\sim 0.17 \mathrm{~mm} \mathrm{~h}^{-1}\right)$ and below the radar design minimum of $1 \mathrm{~mm} \mathrm{~h}^{-1}$ rain rates. Combined with the low intensity clutter that is always present in the radar map this makes tracking and quantifying the precipitation very difficult and illustrates the problem of detecting rainfall below $1 \mathrm{~mm} \mathrm{~h}^{-1}$. As can be seen from the gauge measurements in Fig. $11 \mathrm{i}$ and $\mathrm{j}$ the rain intensity is lower than what would be estimated from the radar. It has to be kept in mind that only $\sim 0.3 \mathrm{~mm}$ of rainfall was measured, i.e. just enough for one tipping by the gauge, resulting in only very limited data for comparison.

Table 3 shows the results of both the HB-forward and MAbackward attenuation correction schemes. Using the gauge located the furthest away from the radar a PIA estimate is found and from there reflectivities are corrected for attenuation towards the radar. The results in Table 3 illustrate that the backward method gives rain rates close to the estimated rain rates of the forward method. This was to be expected as the backward correction scheme only works as long as there is underestimation of the radar compared to the gauge to estimate the attenuation. Where the PIA cannot be estimated the HB-forward scheme is applied. Of course the expected effect of the attenuation correction was very small either way at this low rain intensity. The discrepancy between gauge and radar was to be expected taking into account the lower level of detectable reflectivities and clutter from the radar and the low volumetric resolution of the gauge.

\subsection{Event 2: stratiform rainfall}

During this event on 27 May 1993, which illustrates an underestimation of rainfall by the radar during a stratiform event, rain rates up to $17 \mathrm{~mm} \mathrm{~h}^{-1}$ were measured at the gauge 

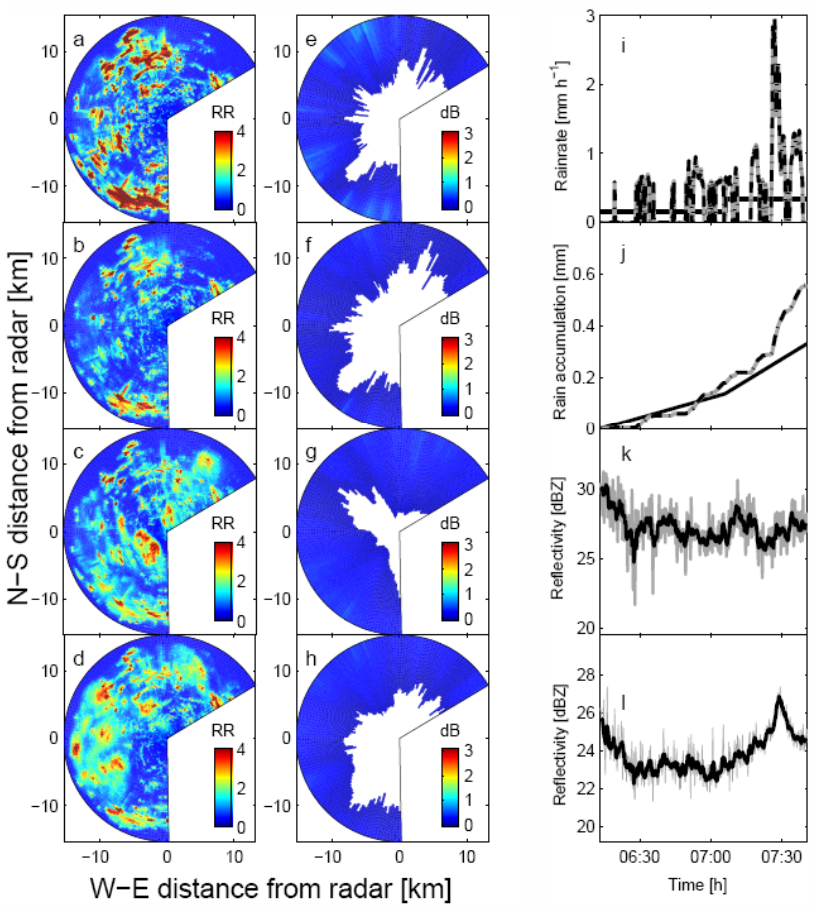

Fig. 11. Low intensity rain event on 15 May 1993. (a-d) Rainfall map from top to bottom: 06:13:27 a.m.; 06:34:15 a.m.; 07:26:32 a.m.; 07:39:50 a.m. (e-h) Attenuation correction corresponding to the rainfall maps shown in $(a-d)$. (i) Rain rate measured by the radar and the gauge at $3.75 \mathrm{~km}$. The black solid line indicates the gauge, the grey solid line the uncorrected radar and the dash-dotted line the HB-forward corrected radar estimate. (j) same as (i), but now accumulated rainfall. (k) Reflectivity of the clutter area north of the radar, with the instantaneous values in grey and the 1 min moving average in black. (l) same as (k) but with reflectivity for entire image.

while the radar did not reach values higher than $10 \mathrm{~mm} \mathrm{~h}^{-1}$. The general appearance of both hyetographs is nevertheless similar, suggesting that the rainfall variability was captured well by SOLIDAR (Fig. 12). At 07:00 a.m. the wind and associated precipitation came from the south, which reached the radar itself at 07:40 a.m. By that time the bulk of the precipitation began to move eastwards, even though some lighter precipitation can be seen to keep traveling northward as well. At around 07:50 a.m. the combined precipitation at the radar clearly caused a dip in the measured reflectivity, as shown in Fig. $12 \mathrm{k}$ and $\mathrm{l}$.

This is a case of high-intensity stratiform rainfall at the radar where, due to wetting of the radar, the signal is more suppressed than is assumed by the HB-forward correction. Even though the shape of the gauge and radar hyetographs look very similar, the significant difference in measured rain intensity even after applying the forward attenuation correction method is a major problem. The results are far more promising when using the backward attenuation correction scheme, as shown in Table 4. The rain rate values found us-
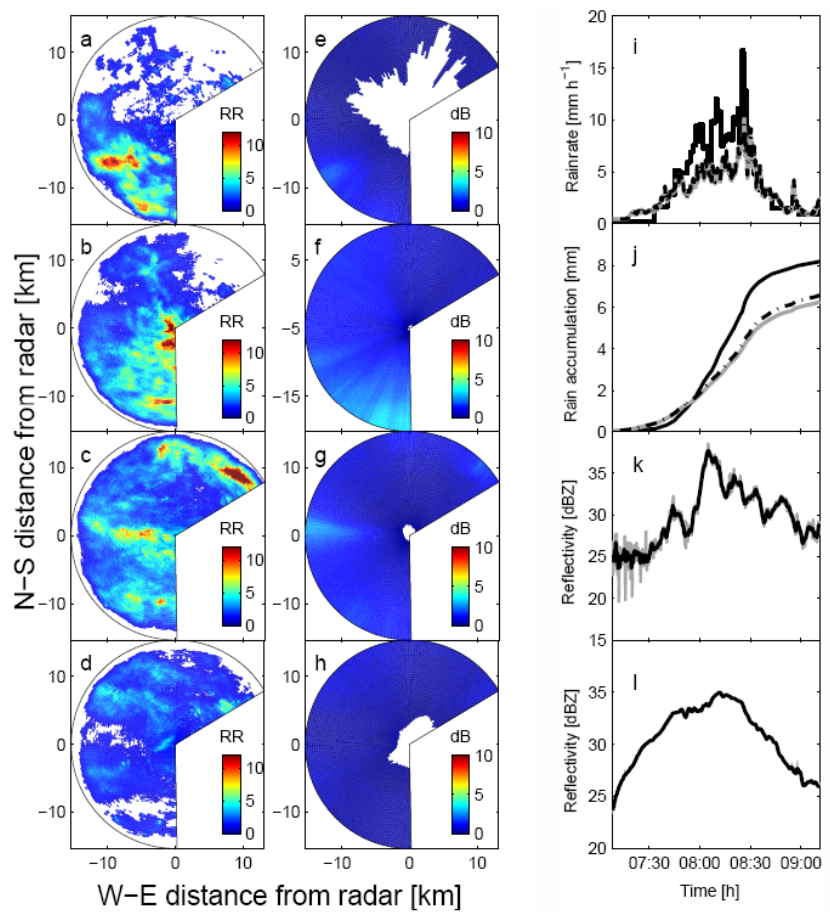

Fig. 12. Stratiform rain event on 27 May 1993. (a-d) Rainfall map from top to bottom: 07:20:35 a.m.; 07:50:05 a.m.; 08:31:06 a.m.; 08:58:30 a.m. (e-h) Attenuation correction corresponding to the rainfall maps shown in $(\mathrm{a}-\mathrm{d})$. (i) Rain rate measured by the radar and the gauge at $3.75 \mathrm{~km}$. The black solid line indicates the gauge, the grey solid line the uncorrected radar and the dash-dotted line the HB-forward corrected radar estimate. (j) same as (i), but now accumulated rainfall. (k) Reflectivity of the clutter area north of the radar, with the instantaneous values in grey and the $1 \mathrm{~min}$ moving average in black. (l) same as (k) but with reflectivity for entire image.

Table 3. Rain accumulation ( $\mathrm{mm}$ ) at gauge locations, estimated using different attenuation correction methods, on 15 May 1993.

\begin{tabular}{lcccc}
\hline Distance & Gauge & $R_{\mathrm{A}}$ & $R_{\mathrm{HB}}$ & $R_{\mathrm{MA}}$ \\
\hline $3750 \mathrm{~m}$ & 0.33 & 0.55 & 0.56 & 0.55 \\
$8006 \mathrm{~m}$ & 0.35 & 0.12 & 0.12 & 0.12 \\
$8006 \mathrm{~m}$ & 0.42 & 0.12 & 0.12 & 0.12 \\
$8864 \mathrm{~m}$ & 0.36 & 0.20 & 0.21 & 0.23 \\
\hline
\end{tabular}

ing this method are actually very similar to those measured by the gauges. This is an ideal case for a backward attenuation correction scheme as the rain intensity is well above the minimum detection threshold, but not so strong as to completely attenuate the signal, as well as mostly uniform along the path over which the PIA is estimated. 
Table 4. Rain accumulation ( $\mathrm{mm}$ ) at gauge locations, estimated using different attenuation correction methods, on 27 May 1993.

\begin{tabular}{lcccr}
\hline Distance & Gauge & $R_{\mathrm{A}}$ & $R_{\mathrm{HB}}$ & $R_{\mathrm{MA}}$ \\
\hline $3750 \mathrm{~m}$ & 8.20 & 6.28 & 6.59 & 9.10 \\
$8006 \mathrm{~m}$ & 11.18 & 6.84 & 7.91 & 11.36 \\
$8006 \mathrm{~m}$ & 12.27 & 6.84 & 7.91 & 11.36 \\
$8864 \mathrm{~m}$ & 11.19 & 6.72 & 7.85 & 11.48 \\
\hline
\end{tabular}
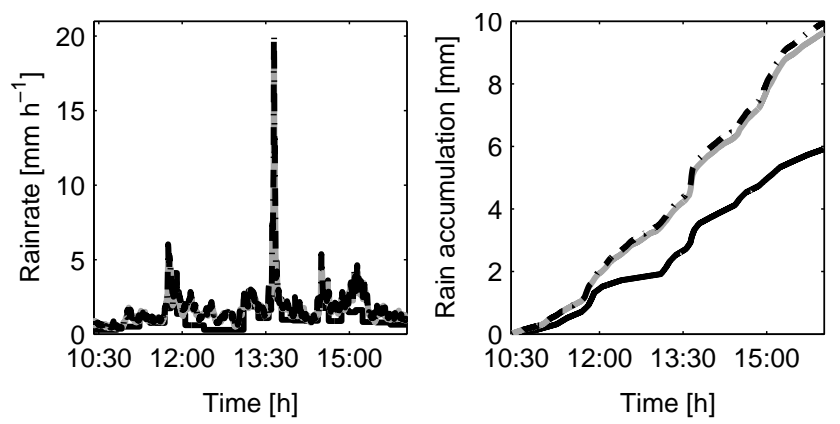

Fig. 13. Rain rate (left) and rainfall accumulation (right) for an event on 16 September 1993, measured by the radar and the gauge at $8 \mathrm{~km}$. The black solid line indicates the gauge, the grey solid line the uncorrected radar and the dash-dotted line the HB-forward corrected radar estimate.

\subsection{Event 3: convective cells}

During this fairly complex event on 16 September 1993, a band of convective cells can be seen to rapidly grow just north and west of the gauge (Fig. 14a-d), while moving slightly westward. This band soon dissolves and soon after several larger convective cells can be seen to form more to the north and south. These cells move in a cyclonal fashion towards the south, with the center of rotation moving from just west of the radar to the radar itself. The first peak can be seen around 11:50 a.m. when a small and short-lived cell grows and dissipates near the gauge at $8 \mathrm{~km}$. Around 01:20 p.m. the center has moved so far from the radar that only a westerly wind is visible. At 01:40 p.m. the strongest peak measured at the gauge can be seen when the now fully northwesterly wind brings a somewhat larger convective cell over the gauge.

What makes this case especially interesting is that, while there is a fair amount of precipitation measured in the radar range, the radar itself remains dry for most of the event. As can be seen from Figs. 13 and $14 i$ and $j$ the hyetograph both at the gauge and that estimated from the radar again have a similar shape, but for the gauge nearest to the radar the center peak is slightly shifted in time compared to the gauge. The accumulated rainfall estimated by the radar at $3.75 \mathrm{~km}$ seems reasonable, but still overestimates by $0.5 \mathrm{~mm}$ when compared with the gauge. For the gauge at $8 \mathrm{~km}$ this is even more pro-
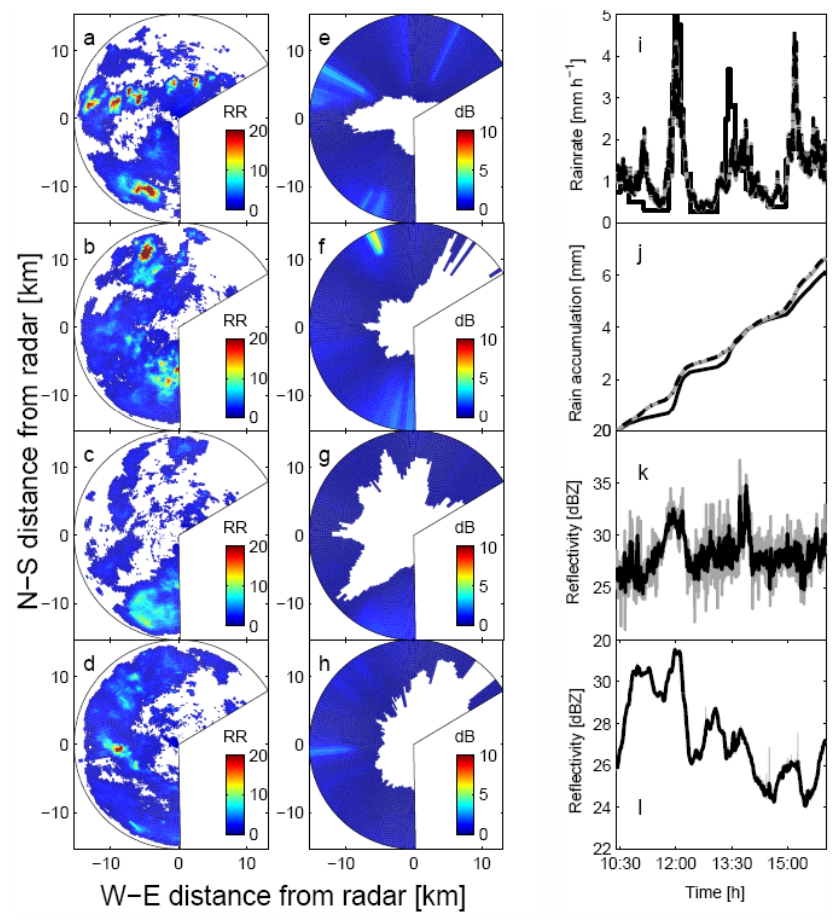

Fig. 14. Convective rain event on 16 September 1993. (a-d) Rainfall map from top to bottom: 10:51:04 a.m.; 11:48:04 a.m.; 00:29:15 p.m.; 01:37:49 p.m. (e-h) Attenuation correction corresponding to the rainfall maps shown in $(\mathrm{a}-\mathrm{d})$. (i) Rain rate measured by the radar and the gauge at $3.75 \mathrm{~km}$. The black solid line indicates the gauge, the grey solid line the uncorrected radar and the dash-dotted line the HB-forward corrected radar estimate. (j) same as (i), but now accumulated rainfall. (k) Reflectivity of the clutter area north of the radar, with the instantaneous values in grey and the 1 min moving average in black. (l) same as (k) but with reflectivity for entire image.

nounced, with nearly twice as much rainfall estimated by the radar.

The significant overestimation is not trivial to explain, but a reason could be found in the fact that in this special case no wet-radome attenuation occurs, as well as highly localized convective cells that may not have been present at the gauge but partially within the radar bin associated with the gauge. As there is overestimation of the radar for nearly the entire event, finding a PIA using the furthest gauge as reference is not possible in most cases. Therefore the MA-backward algorithm also reverts to using the HB-forward scheme and the results for both methods are thus similar (see Table 5).

\subsection{Event 4: weak stratiform precipitation}

On 14 October 1993, a $5 \mathrm{~h}$ period of stratiform precipitation was measured. In the radar image the precipitation can be seen to come from the southwest in bands of very light precipitation. Around 05:45 a.m. stronger stratiform precipitation can be seen to move in from the northeast, which 
Table 5. Rain accumulation ( $\mathrm{mm}$ ) at gauge locations, estimated using different attenuation correction methods, on 16 September 1993 .

\begin{tabular}{lcccr}
\hline Distance & Gauge & $R_{\mathrm{A}}$ & $R_{\mathrm{HB}}$ & $R_{\mathrm{MA}}$ \\
\hline $3750 \mathrm{~m}$ & 6.14 & 6.66 & 6.72 & 6.45 \\
$5450 \mathrm{~m}$ & 8.61 & 12.93 & 13.44 & 12.63 \\
$8006 \mathrm{~m}$ & 5.92 & 9.64 & 9.97 & 9.64 \\
\hline
\end{tabular}

Table 6. Rain accumulation ( $\mathrm{mm}$ ) at gauge locations, estimated using different attenuation correction methods, on 14 October 1993.

\begin{tabular}{lcccc}
\hline Distance & Gauge & $R_{\mathrm{A}}$ & $R_{\mathrm{HB}}$ & $R_{\mathrm{MA}}$ \\
\hline $3750 \mathrm{~m}$ & 9.25 & 6.99 & 7.08 & 7.36 \\
$5450 \mathrm{~m}$ & 8.74 & 8.78 & 8.93 & 9.24 \\
$8006 \mathrm{~m}$ & 8.67 & 6.60 & 6.76 & 6.97 \\
$8006 \mathrm{~m}$ & 8.42 & 6.60 & 6.76 & 6.97 \\
$8864 \mathrm{~m}$ & 6.50 & 7.43 & 7.63 & 8.21 \\
\hline
\end{tabular}

slowly obscures the precipitation coming from the southwest. Around 07:20 a.m. the precipitation is at its maximum and the only rainfall visible is that from the northeast until at 09:50 a.m. precipitation moving in from the west can be seen (see Fig. 15a-d).

Again the precipitation measured by both gauge and radar follow the same pattern, with the exception of the peak with gauge measurements above $2 \mathrm{~mm} \mathrm{~h}^{-1}$, which are underestimated by the radar (Fig. 15i and j). Like the event of 27 May 1993, the wetting of the radome is the most likely cause of this underestimation. Indeed, exactly over this period the strongest precipitation is visible over SOLIDAR, even though the intensity of the rainfall is fairly low. The backward correction yields in this case fairly similar results to the forward correction, but lies slightly higher over the entire range. As the radar at some gauges overestimates and at others underestimates there is no clear correction scheme that outperforms the other.

\subsection{Event 5: squall line}

In this event on 21 September, 1993, a strongly precipitating squall line passed over the line array of gauges and the radar, causing major attenuation. The squall line had a westeast orientation and moved from the south over the line array of rain gauges and radar, as can be seen in Figs. 16a-d. A rain rate of up to $120 \mathrm{~mm} \mathrm{~h}^{-1}$ was measured at the gauge closest to the radar (Fig. 16i and j). The rain rate that was measured at this point by SOLIDAR was far less at only $50 \mathrm{~mm} \mathrm{~h}^{-1}$, which can largely be explained by the strong attenuation along the path, rain on the radar itself or even receiver saturation. After correction for rain-induced attenuation the problem was partly solved, with the maximum rain
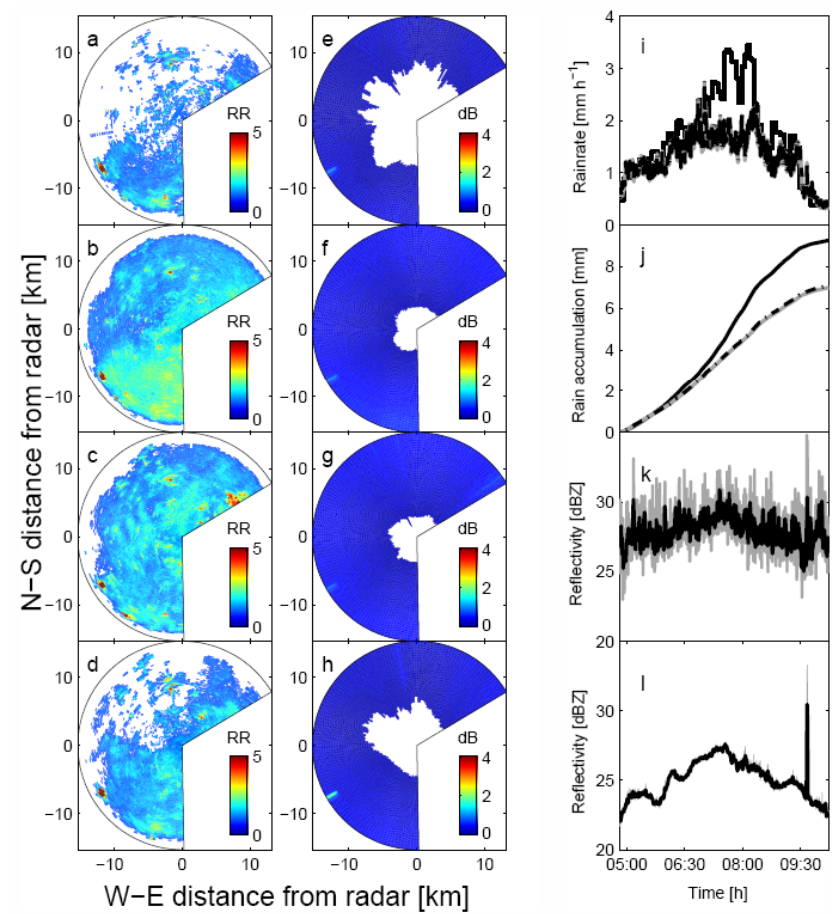

Fig. 15. Weak stratiform precipitation event on 14 October 1993. (a-d) Rainfall map from top to bottom: 04:55:18 a.m.; 06:44:29 a.m.; 08:00:04 a.m.; 09:32:26 a.m. (e-h) Attenuation correction corresponding to the rainfall maps shown in (a-d). (i) Rain rate measured by the radar and the gauge at $3.75 \mathrm{~km}$. The black solid line indicates the gauge, the grey solid line the uncorrected radar and the dash-dotted line the HB-forward corrected radar estimate. (j) same as (i), but now accumulated rainfall. (k) Reflectivity of the clutter area north of the radar, with the instantaneous values in grey and the 1 min moving average in black. (l) same as (k) but with reflectivity for entire image.

rate peak estimated from the radar reflectivity even slightly higher than that measured by the gauges. Using the backward correction scheme the estimated rain rate is still too low, although slightly better (see Table 7).

The total amount of rain accumulated by the gauges was considerably higher, as the duration of the peak measured by the radar is much shorter. This can be explained by looking at Fig. 16e-h, where the strong effect of wet radome attenuation and receiver saturation is clear from the attenuation correction at times 02:58 a.m. and 03:01 a.m. as well as the dip in the clutter reflectivity in Fig. 16k and 1. In Fig. 16k the reflectivity of the clutter area is reduced by nearly $20 \mathrm{~dB}$ from the time the squall line is at the radar until it passes over the clutter area. Also the arrival of the strong precipitation at the radar itself is clear from the average reflectivity for the entire radar image, where a drop by an average of $5 \mathrm{~dB}$ can be seen. Due to the strong attenuation and possible receiver saturation when the squall line arrives at the radar, nearly the entire signal is lost and the radar does not detect 
Table 7. Rain accumulation $(\mathrm{mm})$ at gauge locations, estimated using different attenuation correction methods, on 21 September 1993 .

\begin{tabular}{lcccc}
\hline Distance & Gauge & $R_{\mathrm{A}}$ & $R_{\mathrm{HB}}$ & $R_{\mathrm{MA}}$ \\
\hline $3750 \mathrm{~m}$ & 5.95 & 1.49 & 3.08 & 3.83 \\
$5450 \mathrm{~m}$ & 7.36 & 1.62 & 2.61 & 3.99 \\
$8006 \mathrm{~m}$ & 6.15 & 1.58 & 2.95 & 3.59 \\
$8006 \mathrm{~m}$ & 7.53 & 1.58 & 2.95 & 3.59 \\
$8864 \mathrm{~m}$ & 7.79 & 1.86 & 3.84 & 4.78 \\
\hline
\end{tabular}

the rain beyond the first few hundred meters anymore. Beyond this range the signal is nearly completely lost, making it impossible even to partially correct for it using an attenuation correction scheme.

Also apparent in such a strong squall line is the fact that the structure of the front of the squall line is well defined before reaching the radar, while after passing over the radar only the structure behind the squall line is visible, with no sharp front visible due to attenuation. To make the structure completely visible the attenuation-corrected image after passing over the radar could be combined with an extrapolated image from before arriving at and attenuating the radar. If the highest value would be selected, the merged image should contain the full dynamic range of the squall-line. This method is limited in scope as the spatial structure of the squall line can quickly change such that extrapolation of only a few images ahead is possible.

\section{Summary and conclusions}

We have presented an analysis of 195 rainfall events gathered with the X-band weather radar SOLIDAR and a tipping bucket rain gauge network near Delft, The Netherlands, between May 1993 and April 1994. The high spatial $(120 \mathrm{~m})$ and temporal $(16 \mathrm{~s})$ resolution of the radar (within a $15 \mathrm{~km}$ radius) combined with the extent of the database make this study a climatological analysis of the potential for high-resolution rainfall measurement with non-polarimetric $\mathrm{X}$-band radar over completely flat terrain.

While clutter and attenuation are generally a problem for $\mathrm{X}$-band weather radars, the correction methods outlined in this article perform fairly well. The identification and removal of clutter using either a nearest neighbor or tracking method gives good results with low bias and root mean square error. For small clutter areas the nearest neighbor methods performs best, but with increasing size the tracking method becomes more accurate.

Some underestimation due to attenuation cannot be filtered out by only applying a Hitschfeld-Bordan forward algorithm, as this algorithm does not account for wet radome attenuation (both in convective and stratiform situations) and considering the 3 assumptions listed in Sect. 3.4. During very strong con-
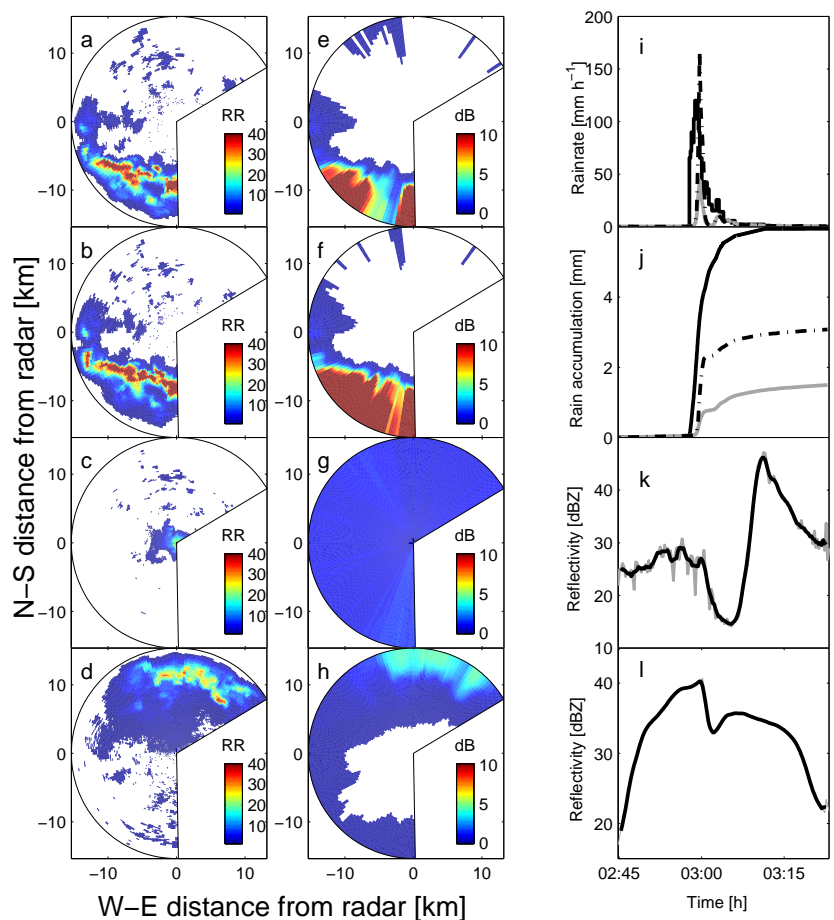

Fig. 16. Squall line passing over the radar on 21 September 1993. (a-d) Rainfall map from top to bottom: 02:52:13 a.m.; 02:58:34 a.m.; 03:01:44 a.m.; 03:15:29 a.m. (e-h) Attenuation correction corresponding to the rainfall maps shown in (a-d). (i) Rain rate measured by the radar and the gauge at $3.75 \mathrm{~km}$. The black solid line indicates the gauge, the grey solid line the uncorrected radar and the dash-dotted line the HB-forward corrected radar estimate. (j) same as (i), but now accumulated rainfall. (k) Reflectivity of the clutter area north of the radar, with the instantaneous values in grey and the 1 min moving average in black. (l) same as (k) but with reflectivity for entire image.

vective conditions complete signal loss can occur, in which case correction is not possible at all. In addition, a maximum correction constraint has to be set for the forward method to avoid numerical instabilities of the algorithm. Along radials where a reference point is available near the maximum radar range a path-integrated attenuation can be estimated, from which a backward attenuation correction can be performed. This method gives better results in strongly precipitating events as well as in cases where wet radome attenuation plays a role. Unlike the forward method, the backward algorithm is numerically stable.

A correction for wet radome attenuation may be partly achieved by using a clutter area as reference to find the amount of reduction in reflectivity and apply this to the entire image. However, this approach has its problems when rainfall is present on the radar or along the path to the clutter area. In addition, there is a tendency for underestimation of the radar rain rate at higher intensities using the $Z-R$ relation derived from independently collected raindrop size distribution 
data. Therefore, using a $Z-R$ relation more like that found from the radar-gauge comparison could yield slightly better results.

While some challenges remain to be tackled, this study has revealed that high-resolution X-band radar does offer a wealth of information on both the temporal and spatial structure of precipitation, in far greater detail than rain gauge networks would ever be able to offer. Therefore, such systems have the potential to provide an invaluable tool for (urban) hydrology, especially if combined with a few gauges for quality control of the radar data. We will continue our research concerning X-band radar estimation of the spacetime variability of precipitation, in particular using the new high-resolution polarimetric X-band radar IDRA (Figueras i Ventura and Russchenberg, 2007, 2008) at the Cabauw Experimental Site for Atmospheric Research (CESAR) in The Netherlands (Russchenberg et al., 2005; Apituley et al., 2008).

Acknowledgements. Financial support for this study has been provided by The Netherlands Organization for Scientific Research (NWO) through Grant EO-058 of The Netherlands Space Research Organization (SRON) and by the Climate Changes Spatial Planning Programme through Project CS-2 ("Monitoring and profiling with the Cabauw Experimental Site for Atmospheric Research"). The authors thank Fred van der Zwan of Delft University of Technology for maintaining the SOLIDAR database.

Edited by: B. Schaefli

\section{References}

Andrieu, H., Creutin, J.-D., and Faure, D.: Use of a weather radar for the hydrology of a mountainous area. Part I: Radar measurement interpretation, J. Hydrol., 193, 1-25, 1997.

Aoyagi, J.: A study on the MTI weather radar system for rejecting ground clutter, Papers in Meteor. and Geophy., 33, 187-243, 1983.

Apituley, A., Russchenberg, H. W. J., van der Marel, H., Bosveld, F., Boers, R., ten Brink, H., de Leeuw, G., Uijlenhoet, R., Arbesser-Rastburg, B., and Röckmann, T.: Overview of research and networking with ground-based remote sensing for atmospheric profiling at the Cabauw Experimental Site for Atmospheric Research (CESAR) - The Netherlands, IEEE Geoscience and Remote Sensing Symposium, IGARSS, 903-906, 2008.

Atlas, D.: Radar calibration - Some simple approaches, B. Am. Meteorol. Soc., 83, 1312-1316, 2002.

Atlas, D. and Banks, H.: The interpretation of microwave reflections from rainfall, J. Meteorol., 8, 271-282, 1951.

Austin, P. M.: Relation between measured radar reflectivity and surface rainfall, Mon. Weather Rev., 115, 1053-1070, 1987.

Battan, L. J.: Radar Observation of the Atmosphere, University of Chicago Press, 324 pp., 1973.

Beard, K. V.: Terminal velocity and shape of cloud and precipitation drops aloft, J. Atmos. Sci., 33, 851-864, 1976.

Berenguer, M., Sempere Torres, D., Corral, C., and SánchezDiezma, R.: A fuzzy logic technique for identifying non- precipitating echoes in radar scans, J. Atmos. Oceanic Technol., 23, 1157-1180, 2005.

Berne, A. and Uijlenhoet, R.: Quantitative analysis of X-band weather radar attenuation correction accuracy, Nat. Hazards Earth Syst. Sci., 6, 419-425, 2006,

http://www.nat-hazards-earth-syst-sci.net/6/419/2006/.

Bringi, V. N. and Chandrasekar, V.: Polarimetric Doppler Weather Radar: Principles and Applications, Cambridge University Press, 2001.

Chandrasekar, V. and Lim, S.: Retrieval of reflectivity in a networked radar environment, J. Atmos. Oceanic Technol., 25, 1755-1767, 2008.

Ciach, G. J.: Local random errors in tipping-bucket rain gauge measurements, J. Atmos. Ocean. Tech., 20, 752-759, 2003.

Ciach, G. J. and Krajewski, W. F.: Analysis and modeling of spatial correlation structure of small-scale rainfall in Central Oklahoma, Adv. Water Resour., 29, 1450-1463, 2006.

Creutin, J.-D., Andrieu, H., and Faure, D.: Use of a weather radar for the hydrology of a mountainous area. Part II: Radar measurement validation, J. Hydrol., 193, 26-44, 1997.

Delrieu, G., Caoudal, S., and Creatin, J.-D.: Feasibility of using mountain return for the correction of ground-based X-band weather radar, J. Atmos. Ocean. Tech., 14, 368-385, 1997.

Delrieu, G., Hucke, L., and Creutin, J.-D.: Attenuation in rain for X- and C-band weather radar systems: sensitivity with respect to the drop size distribution, J. Appl. Meteorol., 38, 57-68, doi:10.1175/1520-0450, 1999.

Figueras i Ventura, J. and Russchenberg, H. W. J.: IDRA: A new instrument for drizzle monitoring, IEEE Geoscience and Remote Sensing Symposium, IGARSS, 3301-3304, doi:10.1109/igarss.2007.4423 550, 2007.

Figueras i Ventura, J. and Russchenberg, H. W. J.: IDRA, a high resolution meteorological radar, 5th European Conference on Meteorology and Radar, ERAD, 2008.

Gage, K. S., Williams, C. R., Johnston, P. E., Ecklund, W. L., Cifelli, R., Tokay, A., and Carter, D. A.: Doppler radar profilers as calibration tools for scanner radars, J. Appl. Meteorol., 39, 2209-2222, 2000.

Gorgucci, E., Scarchilli, G., and Chandrasekar, V.: Calibration of radars using polarimetric techniques, IEEE T. Geosci. Remote Sens., 30, 853-858, 1992.

Hitschfeld, W. and Bordan, J.: Errors inherent in the radar measurement of rainfall at attenuating wavelengths, J. Meteorol., 11, 58-67, 1954.

van de Hulst, H. C.: Light Scattering by Small Particles, John Wiley \& Sons, Inc., 470 pp., 1957.

Joss, J. and Lee, R.: The application of radar-gauge comparisons to operational precipitating profile corrections, J. Appl. Meteorol., 34, 2612-2630, 1995.

Joss, J. and Waldvogel, A.: Raindrop size distribution and sampling size errors, J. Atmos. Sci., 26, 566-569, 1969.

Leijnse, H., Uijlenhoet, R., and Stricker, J. N. M.: Rainfall measurement using radio links from cellular communication networks, Water Resour. Res., 43, W03201, doi:10.1029/2006WR005631, 2007a.

Leijnse, H., Uijlenhoet, R., and Stricker, J. N. M.: Hydrometeorological application of a microwave link: 2. Precipitation, Water Resour. Res., 43, W04417, doi:10.1029/2006WR004989, 2007b.

Leijnse, H., Uijlenhoet, R., and Stricker, J. N. M.: Mi- 
crowave link rainfall estimation: Effects of link length and frequency, temporal sampling, power resolution, and wet antenna attenuation, Adv. Water Resour., 31, 1481-1493, doi:10.1016/j.advwatres.2008.03.004, 2008.

Ligthart, L. P. and Nieuwkerk, L. R.: An X-band solid-state FMCW weather radar, IEE Proc.-F Radar Signal Proces., 137, 418426, 1990.

Marshall, J. S. and Palmer, W. M.: The distribution of raindrops with size, J. Meteorol., 5, 165-166, 1948.

Marshall, J. S., Hitschfeld, W., and Gunn, K. L. S.: Advances in radar weather, Adv. Geophys., 2, 1-56, 1955.

Marzoug, M. and Amayenc, P.: A class of single- and dualfrequency algorithms for rain-rate profiling from a spaceborne radar. Part I: Principle and test from numerical simulations, J. Atmos. Oceanic Technol., 11, 1480-1506, 1994.

Meischner, P.: Weather Radar: Principles and Advanced Applications, Springer, Berlin, 2004.

Russchenberg, H. W. J., Bosveld, F., Swart, D., ten Brink, H., de Leeuw, G., Uijlenhoet, R., Arbesser-Rastburg, B., van der Marel, H., Ligthart, L., Boers, R., and Apituley, A.: Groundbased atmosperic remote sensing in the Netherlands: European Outlook, in: IEICE Trans. Commun., E88-B, 2252-2258, doi:10.1093/ietcom/e88-b.6.2252, 2005.

Ryde, J. W.: The attenuation and radar echoes produced at centimeter wavelengths by various meteorological phenomena, in: Meteorological Factors in Radio Wave Propagation, Physical Society, London, 1946.

Sánchez-Diezma, R., Sempere Torres, D., Creutin, J.-D., Zawadzki, I., and Delrieu, G.: Factors affecting the precision of radar measurement of rain: Assessment from an hydrological perspective, in: Preprints of the 30th International Conference on Radar Meteorology, American Meteorological Society, Boston, 573-575, 2001.

Siggia, A. D. and Passarelli, R. E.: Gaussian model adaptive processing (GMAP) for improved ground clutter cancellation and moment calculation, Proc. ERAD 2004, 2, 421-424, 2004.
Simpson, J., Adler, R., and North, G.: A proposed Tropical Rainfall Measuring Mission (TRMM), Bull. Am. Meteorol. Soc., 69, 278-295, 1988.

Steiner, M. and Smith, J. A.: Use of three-dimensional reflectivity structure for automated detection and removal of nonprecipitating echoes in radar data, J. Atmos. Ocean. Tech., 19, 673-686, 2002.

Stephens, G. L. and Kummerov, C. D.: The remote sensing of clouds and precipitation from space, J. Atmos. Sci., 64, 37423765, 2007.

Stratmann, E., Atlas, D., Richter, J. H., and Jensen, D. R.: Sensitivity calibration of a dual-beam vertically pointing FM-CW radar, J. Appl. Meteorol., 10, 1260-1265, 1971.

Uijlenhoet, R.: Raindrop size distributions and radar reflectivityrain rate relationships for radar hydrology, Hydrol. Earth Sys. Sci., 5, 615-627, 2001.

Uijlenhoet, R.: Climate and the Hydrological Cycle, chap. Precipitation physics and rainfall observation, IAHS Press, Wallingford, 59-97, 2008.

Uijlenhoet, R. and Berne, A.: Stochastic simulation experiment to assess radar rainfall retrieval uncertainties associated with attenuation and its correction, Hydrol. Earth Syst. Sci., 12, 587-601, 2008, http://www.hydrol-earth-syst-sci.net/12/587/2008/.

Uijlenhoet, R., Stricker, J. N. M., and Russchenberg, H. W. J.: Application of X-and S-band radars for rain rate estimation over an urban area, Phys. Chem. Earth, 22, 259-264, 1997.

Unal, C.: Spectral polarimetric radar clutter suppression to enhance atmospheric echoes, J. Atmos. Ocean. Tech., 26, 1781-1797, doi:10.1175/2009JTECHA1170.1, 2009.

Wessels, H. R. A.: Metingen van regendruppels in De Bilt, Tech. Rep. W. R. 72-6, R. Neth. Meteorol. Inst., De Bilt, 41 pp., 1972 (in Dutch).

Zawadzki, I.: Factors affecting the precision of radar measurements of rain, in: Preprints of the 22nd conference on Radar Meteorology, 251-256, American Meteorological Society, Boston, 1984. 